10

\title{
Электрохромные стекла с раздельным регулированием пропускания видимого света и ближнего инфракрасного излучения (обзор)
}

\author{
(C) В.А. Майоров \\ Новгородский государственный университет имени Ярослава Мудрого, \\ 173003 Великий Новгород, Россия \\ e-mail: Vitaly.Mayorov@novsu.ru
}

Поступила в редакцию 07.09.2018 г.

В окончательной редакции 07.09.2018 г.

Принята к публикации 28.12.2018 г.

В кристаллических наночастицах восстановленного (легированного кислородными вакансиями) триоксида вольфрама и диоксида титана, легированного пяти- или шестивалентными металлами, при электрохимической инжекции в них сначала электронов, а затем и положительно заряженных ионов последовательно включаются механизмы плазмонного и поляронного ослабления солнечного излучения. Применение изготовленных из таких наночастиц мезопористых электродов в электрохромном стекле дает возможность обеспечить динамическое раздельное регулирование пропускания видимого света и ближнего инфракрасного излучения и реализовать плавное изменение состояния стекла последовательно от светлого теплого к светлому холодному и далее к темному холодному. Выполнен анализ результатов исследований электрохромных стекол с раздельным регулированием пропускания видимого света и ближнего инфракрасного излучения. Обобщены сведения по влиянию структурных характеристик мезопористого электрода и вида электролита на оптические спектральные свойства, длительность переходных процессов и циклическую стабильность устройства. Установлено, что электрохромные стекла с наноструктурными однокомпонентными электродами из восстановленного триоксида вольфрама и легированного диоксида титана обладают оптимальными оптическими, эксплуатационными и технологическими свойствами.

DOI: $10.21883 / \mathrm{OS} .2019 .04 .47521 .264-18$

\section{Введение}

В опубликованной около года назад работе [1] были приведены результаты первых исследований электрохромных стекол с раздельным регулированием пропускания видимого света и ближнего инфракрасного (БИК, NIR - near infrared) излучения. Ввиду актуальности проблемы к ее разработке подключились коллективы исследователей в различных странах и за короткое время опубликовано значительное количество новых результатов. Их анализ и обобщение позволяют отделить индивидуальные особенности исследованных устройств и выявить общие закономерности происходящих в них процессов и определить направление продолжения исследований с целью получения работоспособного опытного электрохромного стекла оконного размера и его последующей коммерческой реализации. Предлагаемый здесь материал приводится в дополнение к изложенному ранее в работе [1].

Вначале используем самые необходимые общие сведения.

На внешней поверхности стекла падающее солнечное излучение частично отражается и частично проходит внутрь стекла. При прохождении через стекло излучение испытывает многократные внутренние отражения и частично поглощается, остаток излучения выходит через внутреннюю поверхность. При этом выполняется соотношение

$$
\tau+\rho+\alpha=1
$$

где $\tau, \rho, \alpha-$ спектральные коэффициенты пропускания, отражения и поглощения стекла соответственно. Соотношение между величинами $\tau, \rho, \alpha$ существенно изменяется в зависимости от длины волны $\lambda$ падающего излучения.

В диапазоне от 0.3 до $3.5 \mu \mathrm{m}$ заключено 99\% энергии солнечного излучения. Весь диапазон солнечного излучения делят на три части:

- ультрафиолетовое (УФ) излучение с длиной волны в диапазоне $0.3<\lambda<0.38 \mu \mathrm{m}$, в котором заключено $5 \%$ энергии солнечного излучения;

- видимый свет $0.38<\lambda<0.78 \mu \mathrm{m}$ содержит 40\% солнечной энергии;

- БИК излучение $0.78<\lambda<3.5 \mu \mathrm{m}$ включает 55\% солнечной энергии.

БИК излучение составляет более половины всего потока солнечной энергии, после прохождения через окно оно не участвует в естественном освещении и вызывает перегрев помещения летом. Для удаления этой теплоты и сохранения комфортных условий требуются 


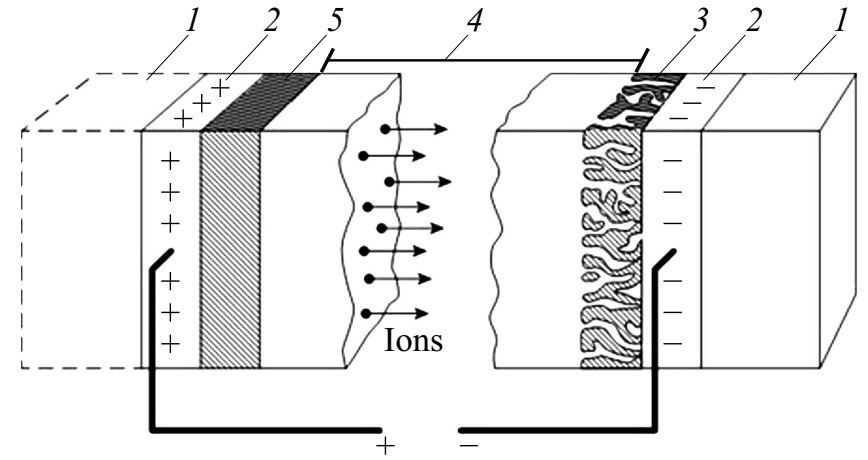

Рис. 1. Схема электрохромного стекла [2]: 1 - прозрачное стекло или гибкая полимерная пленка; 2 - прозрачный электропроводящий слой; 3 - катодный электрохромный слой; 4 - проводник ионов - электролит; 5 - источник ионов или анодный электрохромный слой.

значительные затраты энергии на охлаждение с помощью системы кондиционирования. Поэтому блокирование БИК излучения представляет важную задачу, особенно в теплых климатических зонах в летний период.

Для характеристики стекол обычно используют оптические показатели, усредненные по отдельным диапазонам (УФ, видимый свет, БИК и дальнее инфракрасное излучение) или по всему диапазону солнечного излучения. При этом используют соответствующие нижние индексы. Например, коэффициент пропускания видимого света $\tau_{\text {vis, }}$ БИК излучения $\tau_{\mathrm{NIR}}$ и всего солнечного излучения $\tau_{s}$.

\section{Электрохромные стекла с поляронным механизмом ослабления солнечного излучения}

Электрохромное стекло - это устройство, в котором постоянное электрическое напряжение используется для контроля и регулирования интенсивности проходящего через него солнечного излучения.

Схема электрохромного стекла изображена на рис. 1 . Оно состоит из размещенной между двумя прозрачными стеклами 1 пятислойной электрохимической ячейки 2-5. В коммерческих электрохромных стеклах используется твердый или полимерный электролит. При этом толщина пятислойной структуры в первом варианте около $1 \mu \mathrm{m}$, во втором - около $0.75 \mathrm{~mm}$.

Центральная часть 4 электрохимической ячейки проводник ионов (электролит) - может состоять из органического материала (клейкий полимер) или неорганического соединения (обычно оксидная пленка). Ионы обычно имеют малый размер для того, чтобы сохранять подвижность: протоны $\mathrm{H}^{+}$или $\mathrm{Li}^{+}$. Проводник ионов не должен проводить электроны и находится в контакте с катодным электрохромным слоем 3, который обладает смешанной проводимостью и хорошо проводит как ионы, так и электроны. Другой поверхностью проводник ионов контактирует со слоем 5, выполняющим функцию источника ионов. Идеальный вариант - если этот слой 5 одновременно выполняет функцию электрохромного слоя, дополнительного к первому слою 3. Центральная трехслойная структура 3-5 расположена между двумя прозрачными электропроводящими покрытиями 2. Покрытия обладают только электронной проводимостью. Прозрачные электропроводящие покрытия являются одним из наиболее дорогостоящих элементов электрохромных изделий.

Когда постоянное напряжение около одного вольта прикладывается между электропроводящими покрытиями 2, ионы инжектируются из источника ионов 5 в электрохромный слой 3. Электроны инжектируют в катодный электрохромный слой 3 из электропроводящего покрытия. Электроны вызывают изменение оптического поглощения - окрашивание этого слоя. Дополнительный эффект достигается в идеальном варианте, когда при экстракции ионов окрашивается и слой 5 , который в этом случае выполняет функцию не только источника ионов, но также и функцию электрохромного слоя.

Изменение полярности напряжения возвращает устройство в исходное состояние. Степень затемнения может быть зафиксирована на любом промежуточном уровне и длительное время оставаться неизменной без электрического тока в цепи - „эффект памяти“. Это означает, что изменение оптического состояния происходит только при инжекции - экстракции зарядов (при наличии электрического тока).

В настоящее время в качестве катодного электрохромного материала практически во всех коммерческих изделиях используется аморфный триоксид вольфрама $\mathrm{WO}_{3}$. Суть электрохромного эффекта состоит в том, что при двойной инжекции в пленку триоксида вольфрама легких ионов $\left(\mathrm{H}^{+}, \mathrm{Li}^{+}, \mathrm{Na}^{+}, \mathrm{K}^{+}\right)$и электронов она окрашивается в голубой цвет.

Процессы окрашивания и обесцвечивания связаны с химической реакцией образования соединения с переменным составом [2,3]:

$$
\left[\mathrm{WO}_{3}+x \mathrm{M}^{+}+x e^{-}\right]_{\text {colorless }} \leftrightarrow\left[\mathrm{M}_{x} \mathrm{WO}_{3}\right]_{\text {blue }},
$$

где $\mathrm{M}^{+}$может быть $\mathrm{H}^{+}, \mathrm{Li}^{+}, \mathrm{Na}^{+}, \mathrm{K}^{+}, e^{-}$- электрон, $x$ - стехиометрический коэффициент, изменяющийся в диапазоне $0-1$.

Электроны, инжектируемые внутрь структуры $\mathrm{WO}_{3}$ вместе с ионами $\mathrm{M}^{+}$, локализуются на ионах металла $\mathrm{W}_{i}^{6+}$, уменьшая их заряд до $\mathrm{W}_{i}^{5+}$ и образуя малые поляроны:

$$
\mathrm{W}_{i}^{6+}+e^{-}=\mathrm{W}_{i}^{5+} .
$$

Компенсатором возникшего заряда являются катионы $\mathrm{M}^{+}$. Поглощая фотоны света с энергией около $h v \sim 1.4 \mathrm{eV}$ из диапазона солнечного излучения, эти электроны получают энергию, достаточную для перехода на соседние ионы $\mathrm{W}_{j}^{6+}$ (межвалентный перенос или 
перенос поляронов) в соответствии с уравнением:

$$
\mathrm{W}_{i}^{5+}+\mathrm{W}_{j}^{6+}+h v \rightarrow \mathrm{W}_{i}^{6+}+\mathrm{W}_{j}^{5+} .
$$

При переходе с атома на атом электроны поглощают фотоны с энергией в широкой полосе спектра с центром около $850 \mathrm{~nm}$ в области БИК излучения, в том числе частично в диапазоне видимого света от зеленого до красного, что и вызывает окрашивание проходящего через устройство солнечного света в голубой цвет. При увеличении концентрации инжектированного заряда возрастает интенсивность окраски, при этом происходит сдвиг максимума полосы поглощения в сторону более коротких длин волн. При экстракции заряда пленка возвращается в прозрачное неокрашенное состояние.

В качестве анодного электрохромного материала применяют вещество „прусский голубой“ - KFe $\left[\mathrm{Fe}(\mathrm{CN})_{6}\right]$. Реакция его окрашивания в голубой цвет описывается уравнением:

$\mathrm{KFe}\left[\mathrm{Fe}(\mathrm{CN})_{6}\right]_{\text {colorless }} \leftrightarrow\left[\mathrm{Fe}^{3+}+\left[\mathrm{Fe}\left(\mathrm{CN}_{6}\right)\right]^{3-}+\mathrm{K}^{+}+e^{-}\right]_{\text {blue }}$.

Поглощение фотонов при переходе электронов между $\mathrm{Fe}^{2+}$ и $\mathrm{Fe}^{3+}$ вызывает окрашивание проходящего света в голубой цвет. В сочетании с триоксидом вольфрама это вещество существенно повышает эффективность устройства.

На рис. 2 приведены два примера изменения спектральных свойств электрохромного стекла при изменении электрического напряжения. Наряду с аморфным $\mathrm{WO}_{3}$ в последнее время все чаще используются мезопористые электрохромные слои из кристаллического диоксида титана $\mathrm{TiO}_{2}$. Отчетливо видно, как максимум поглощения $\mathrm{WO}_{3}$ при уменьшении потенциала смещается около $850 \mathrm{~nm}$ в сторону более коротких длин волн. Механизм ослабления видимого света в слоях аморфного $\mathrm{WO}_{3}$ и нанокристаллов $\mathrm{TiO}_{2}$ аналогичен. $\mathrm{B}$ слое $\mathrm{TiO}_{2}$ поглощение света происходит вследствие локализации инжектируемых электронов на сайтах $\mathrm{Ti}^{4+}$ с образованием $\mathrm{Ti}^{3+}$ малых поляронов. Для нанокристаллов $\mathrm{TiO}_{2}$ максимум поглощения излучения расположен около $730 \mathrm{~nm}$.

Основной недостаток электрохромных стекол - при увеличении напряжения они ослабляют не только видимый свет, но и БИК излучение. Причем ослабление излучения в обоих диапазонах происходит одновременно, не раздельно. Необходимо обеспечить последовательное ослабление сначала БИК излучения, а затем - видимого света.

Обобщение результатов исследований обычных электрохромных стекол выполнено в работах $[2,3]$, характеристики аналогичных коммерческих изделий приведены в работах $[6,7]$.
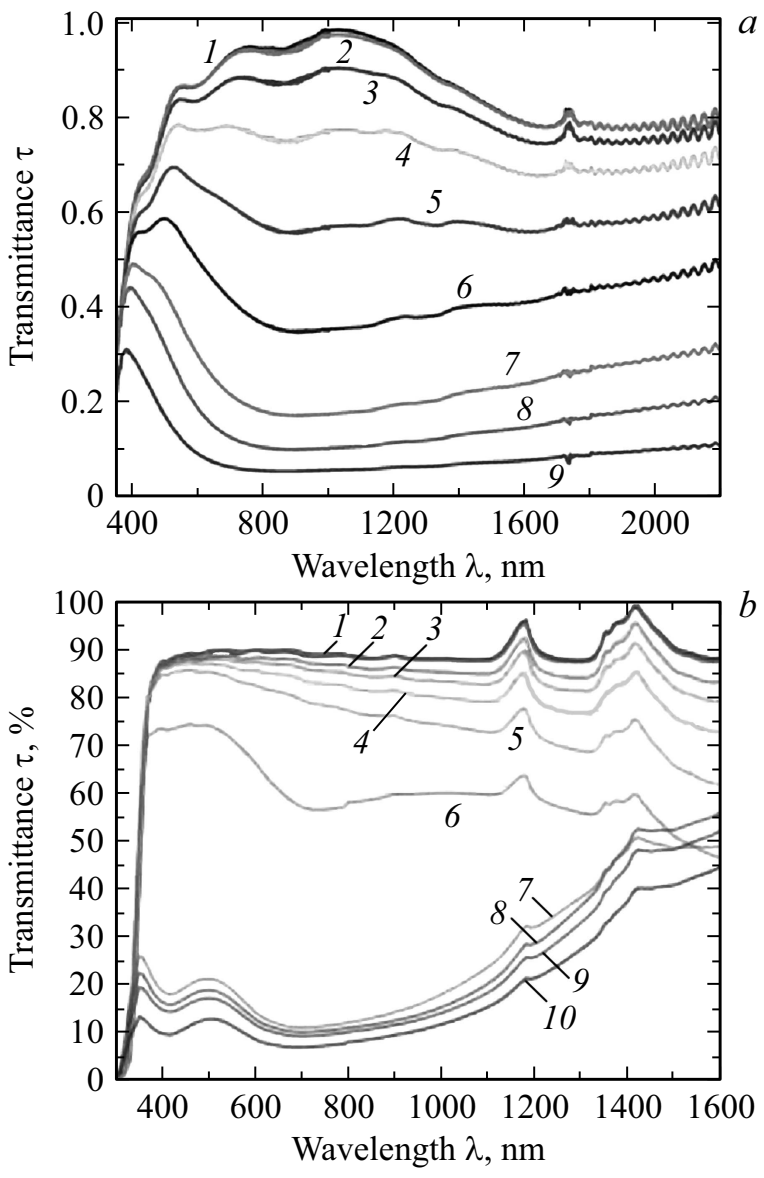

Рис. 2. Спектры пропускания электрохимической ячейки с катодным электрохромным слоем из оксидов переходных металлов с внедренными ионами $\mathrm{Li}^{+}$при различных значениях потенциала: (a) аморфный $\mathrm{WO}_{3}$, максимум поглощения $\sim 800 \mathrm{~nm}[4]: 4.0$ (1), 3.0 (2), 2.9 (3), 2.8 (4), 2.7 (5), 2.6 (6), $2.4(7), 2.3(8), 2.0 \mathrm{~V}(9)$. (b) электрод толщиной $1 \mu \mathrm{m}$ из нанокристаллов $\mathrm{TiO}_{2}$ размером $10 \mathrm{~nm}$, максимум поглощения $\sim 730 \mathrm{~nm}[5]: 0 \mathrm{~V}(1),-0.8(2),-1.0(3),-1.05(4),-1.10$ (5), $-1.20(6),-1.25(7),-1.3(8),-1.4(9),-1.6 \mathrm{~V}(10)$.

\section{Плазмонный механизм ослабления БИК излучения}

Динамическое плазмонное модулирование БИК излучения за счет электрохимической инжекции электронов в плазмонные наночастицы из оксидов ITO и AZO было впервые экспериментально реализовано группой исследователей в США под руководством D.J. Milliron в 2011-2014 гг. ITO (Indium Tin Oxide) - легированный оловом оксид индия $\mathrm{In}_{2} \mathrm{O}_{3}: \mathrm{Sn}, \mathrm{AZO}$ (Aluminum doped Zinc Oxide) - легированный алюминием оксид цинка $\mathrm{ZnO}: \mathrm{Al}$.

Подробно ход исследования этого явления и достигнутые результаты освещены в предыдущей работе [1]. Здесь кратко изложим суть этого явления.

Используемая электрохимическая ячейка представляет слоистую структуру, основными элементами которой 


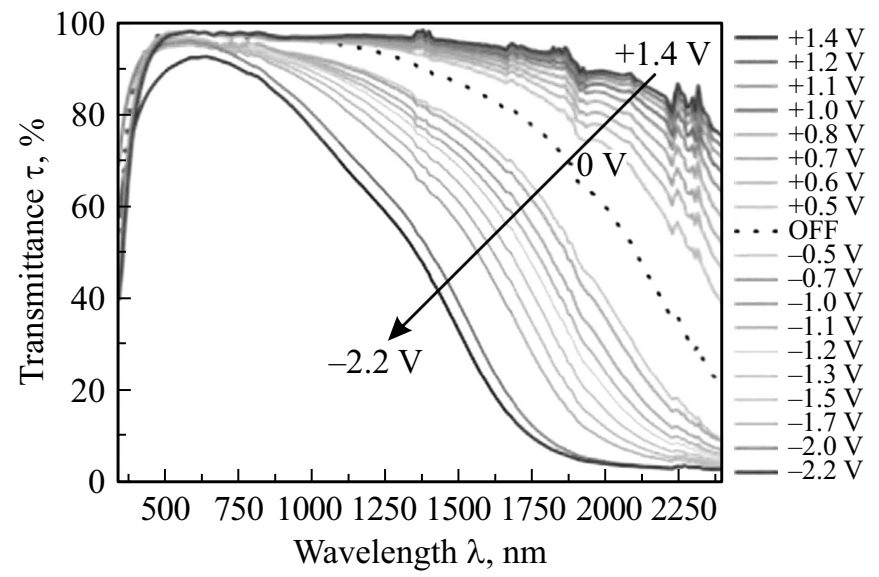

Pис. 3. Спектры пропускания нанокристаллической пленки ITO при значениях ее потенциала $+1.4,1.2,1.1,1.0,0.8,0.7$, $0.6,0.5,0,-0.5,-0.7,-1.0,-1.1,-1.2,-1.3,-1.5,-1.7$, $-2.0,-2.2 \mathrm{~V}[8]$.

являются два стекла с прозрачным электропроводящим оксидным покрытием, обычно ITO или FTO (Fluorine doped Tin Oxide - легированный фтором оксид олова $\left.\mathrm{SnO}_{2}: \mathrm{F}\right)$ и содержащим ионы лития $\mathrm{Li}^{+}$электролитом между ними. Катодный тонкий электрохромный слой выполнен из плазмонных наночастиц. Структура ячейки выражается формулой: стекло/ІТО/слой плазмонных наночастиц/электролит/ITО/стекло.

При отсутствии разности потенциалов ионы $\mathrm{Li}^{+}$равномерно распределены по объему электролита. Плазмонные наночастицы находятся в нейтральном состоянии и ослабляют проходящее через электрохромную ячейку солнечное излучение за счет локализованного плазмонного резонанса (ЛПР) в соответствии с их исходным фиксированным состоянием.

При подаче отрицательного потенциала на ITO покрытие со слоем плазмонных наночастиц электроны инжектируются внутрь наночастиц и создают отрицательный заряд. Положительные ионы $\mathrm{Li}^{+}$из электролита под действием электрического поля перемещаются к поверхности наночастиц и нейтрализуют их отрицательный заряд, образуя двойной электрический слой. В результате происходит емкостное (конденсаторное) увеличение концентрации электронов в наночастице. Увеличение концентрации электронов внутри наночастиц приводит к повышению частоты плазмонного резонанса и к „голубому“ сдвигу полосы ослабления проходящего солнечного света. Величина этого сдвига возрастает при увеличении разности потенциалов на ячейке.

Показательные результаты приведены на рис. 3. Электрохимическая ячейка имеет структуру: стекло/FTO/пленка ITO наночастиц/электролит/Pt/FTO/стекло. Электрохромная пленка толщиной $1.1 \mu \mathrm{m}$ состоит из наночастиц ITO средним размером $10 \mathrm{~nm}$ и имеет высокопористую регулярную структуру. Эти результаты интересны тем, что изменение пропускания электро- хромной пленки зафиксировано в широком диапазоне изменения ее потенциала от исходного нейтрального состояния в обе стороны. При этом особый интерес имеют результаты при увеличении потенциала электрохромной пленки в положительную сторону. В этом случае из наночастиц пленки происходит удаление электронов, явление плазмонного резонанса постепенно ослабевает и уменьшается ослабление проходящего излучения с перемещением полосы ослабления вправо. При потенциале $+1.4 \mathrm{~V}$ электрохромная пленка практически полностью теряет свою поглощательную способность в области БИК излучения.

Величина изменения (модуляции) БИК излучения при использовании электрохромной пленки из ITO наночастиц имеет ограниченное значение. Причина в том, что максимум полосы резонансного поглощения исходных наночастиц ITO находится около $1600 \mathrm{~nm}$, тогда как основная часть солнечного БИК излучения (более 75\%) располагается в диапазоне 780-1400 nm.

Обобщение результатов исследований свойств и методов изготовления наночастиц из легированных металлических оксидов выполнено в обзорных работах $[9,10]$, список использованных источников в которых содержит соответственно 374 и 611 наименований.

Для более эффективного модулирования БИК излучения необходимы материалы с плазмонной резонансной длиной волны в диапазоне 900-1200 nm. Такими материалами являются восстановленный (легированный кислородными вакансиями) триоксид вольфрама $\mathrm{WO}_{3-x}[11]$ и диоксид титана $\mathrm{TiO}_{2}$, легированный пяти или шестивалентными металлами [12].

\section{Электрохромные стекла с раздельным регулированием пропускания видимого света и ближнего инфракрасного излучения}

\section{Исходные результаты - однослойные двухкомпонентные электрохромные электроды}

После первых удачных экспериментов по модуляции БИК излучения появилась возможность реализовать более сложную систему по „двухполосному“ раздельному регулированию БИК излучения и видимого света. Инициатором снова выступила группа исследователей под руководством D.J. Milliron [13]. При этом были использованы все предыдущие наработки по формированию структурированного высокопористого слоя наночастиц.

Замысел электрохромного раздельного регулирования пропускаемых видимого света и БИК излучения состоит в том, чтобы при постепенном изменении напряжения на электрохромном слое обеспечить последовательное подавление соответствующих участков (полос) солнечного спектра. Желательная последовательность такова: 


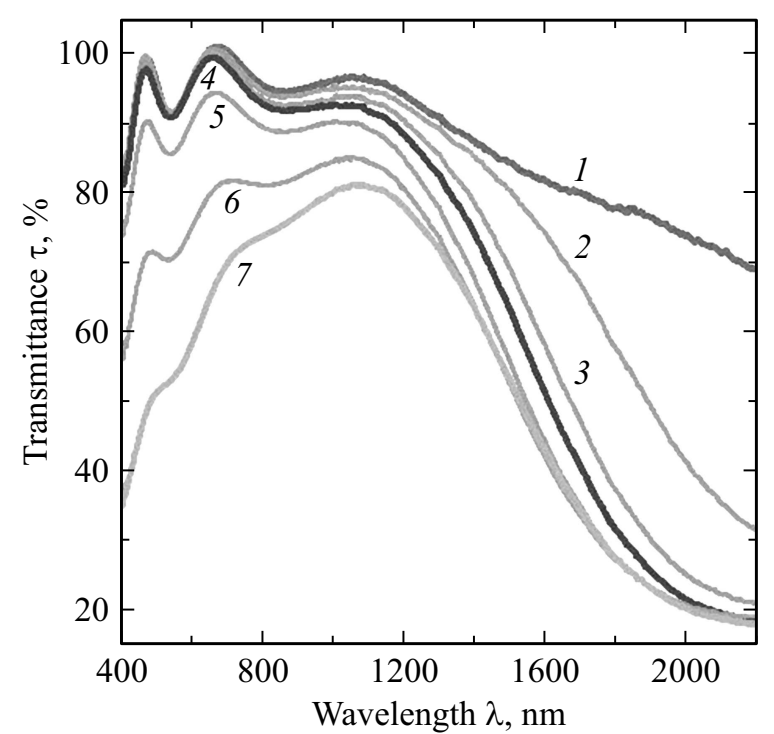

Pис. 4. Спектры пропускания электрохромной ячейки с однослойным двухкомпонентным наноструктурным ITO $+\mathrm{NbO}_{x}$ электродом при значениях его потенциала [13]: 4.0 (1), 3.0 (2), $2.5(3), 2.3$ (4), 2.0 (5), $1.7(6), 1.5 \mathrm{~V}(7)$.

- сначала подавляется БИК излучение и поступление теплоты в помещение;

- затем постепенно подавляется видимый свет (затенение) при избыточном интенсивном потоке солнечного излучения. При этом последовательно реализуются следующие состояния стекла: „светлое теплое“ (прозрачное) - „светлое холодное“ (блокирование БИК излучения) — „темное холодное“ (блокирование БИК излучения и видимого света).

Вначале использовали два различных материала:

- плазмонные наночастицы для динамического регулирования БИК излучения при низком напряжении на электроде;

- материалы с электрохромным ослаблением видимого света за счет поляронного эффекта при инжекции электронов и ионов $\mathrm{Li}^{+}$или $\mathrm{H}^{+}$при более высоком напряжении.

Следует отметить, что к этому времени уже было установлено наличие двух механизмов ослабления солнечного излучения в нанокристаллах восстановленного триоксида вольфрама $\mathrm{WO}_{3-x}$ [11]. Основной механизм - плазмонный резонанс с полосой поглощения с центром около $1550 \mathrm{~nm}$. Второй, вспомогательный оптическое поглощение с полосой с центром около $850 \mathrm{~nm}$ при внедрении электронов и ионов $\mathrm{Li}^{+}$внутрь кристаллической решетки.

В первоначальном исследовании [13] при использовании пары материалов ITO $+\mathrm{NbO}_{x}$ наночастицы ITO недостаточно ослабляют БИК излучение вследствие того, что максимум их полосы поглощения $(\sim 1600 \mathrm{~nm})$ расположен за пределами основной части солнечного БИК излучения (рис. 4). Наночастицы из восстановленных оксидов вольфрама $\mathrm{WO}_{3-x}$ обладают высокой спо- собностью подавления БИК излучения, потому что максимумы их полос поглощения находятся вблизи $900 \mathrm{~nm}$. Поэтому в следующей работе [14] была использована пара материалов $\mathrm{WO}_{3-x}+\mathrm{NbO}_{x}$. Нанокристаллы $\mathrm{WO}_{3-x}$ ослабляют БИК излучение, аморфный $\mathrm{NbO}_{x}$ ослабляет видимый свет.

Особое внимание уделено формированию структуры электрохромной пленки. Размер нанокристаллов $\mathrm{WO}_{3-x}$ равен $4.3 \mathrm{~nm}$. Сначала из этих частиц была сформирована регулярная пористая структура пористостью 71\% со средним радиусом пор $53 \mathrm{~nm}$. После этого пористая структура была заполнена аморфным $\mathrm{NbO}_{x}$. Полученная двухкомпонентная матрица имеет пористость 9\% при среднем радиусе пор $1.7 \mathrm{~nm}$ и радиусе капиллярных каналов $1.5 \mathrm{~nm}$. Непрерывная сеть связанных капиллярными каналами пор обеспечивает возможность перемещения ионов $\mathrm{Li}^{+}$по всей толщине электрохромной пленки. Изготовленная таким способом двухкомпонентная электрохромная пленка проявляет независимое двухполосное модулирование солнечного излучения при изменении напряжения на ней. Спектры пропускания при различных напряжениях изображены на рис. 5.

При потенциале на пленке $4 \mathrm{~V}$ оба компонента $\left(\mathrm{WO}_{3-x}\right.$ и $\left.\mathrm{NbO}_{x}\right)$ полностью разряжены, часть свободных электронов из них удалена. Пленка пропускает видимый свет и БИК излучение, и ее состояние светлое теплое. При понижении потенциала до $2.3 \mathrm{~V}$ постепенно возрастает концентрация свободных электронов в плазмонных нанокристаллах $\mathrm{WO}_{3-x}$. Это приводит к увеличению интенсивности плазмонного резонанса и постепенному ослаблению пропускаемого БИК излуче-

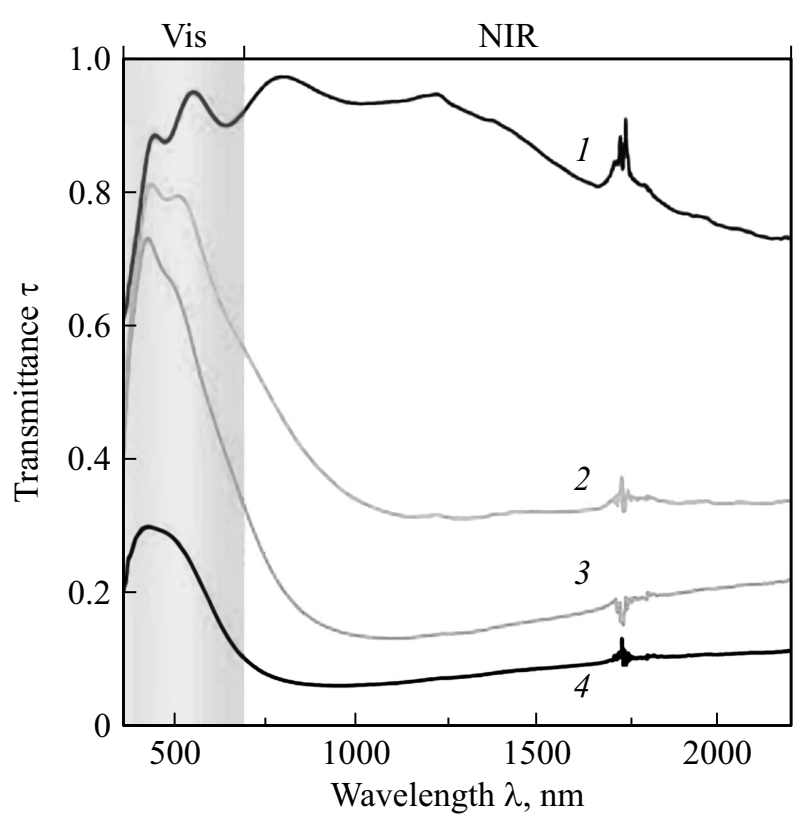

Рис. 5. Спектры пропускания электрохромной ячейки с однослойным двухкомпонентным наноструктурным $\mathrm{WO}_{3-x}+\mathrm{NbO}_{x}$ электродом при значениях его потенциала [14]: 4 (1), $2.3(2,3)$, $1.5 \mathrm{~V}$ (4). Состояние 2 зафиксировано через $1 \mathrm{~min}$ после переключения напряжения, состояние 3 - через $3 \mathrm{~min}$. 
ния. Максимум полосы поглощения около $900 \mathrm{~nm}$. При этом ослабляется и часть видимого света, в основном в его „красной“ части спектра. В этом светлом холодном состоянии пленка блокирует значительную часть БИК излучения и пропускает видимый свет. При дальнейшем понижении потенциала от 2.3 до $1.5 \mathrm{~V}$ электроны и компенсирующие их ионы $\mathrm{Li}^{+}$внедряются внутрь $\mathrm{NbO}_{x}$. Это приводит к возникновению и постепенной интенсификации поляронного механизма ослабления видимого света. Пленка становится темной холодной. Она имеет серо-голубой цвет постепенно увеличивающей глубины. В темном холодном состоянии пленка практически полностью ослабляет БИК излучение.

В работе [15] был испытан образец электрохромного стекла с полимерным гель-электролитом. Значение этого устройства состоит в том, что оно создает основу для изготовления электрохромного стекла оконного размера, которые могут быть созданы только с твердым или полимерным электролитом.

Приведенные результаты позволяют сделать заключение, что в результате цикла исследований коллектив под руководством D.J. Milliron установил принципы и реализовал опытное устройство динамического независимого модулирования БИК излучения и видимого света, характеристики которого отвечают требованиям для реальных умных окон.

\section{Новые результаты}

Разработки электрохромного стекла для динамического раздельного регулирования пропускаемых видимого света и БИК излучения были подхвачены и активно продолжены группами исследователей сначала из Италии [16-19], а затем из Китая [20,21] и Сингапуpa $[4,22,23]$. Число опубликованных работ по этой теме быстро увеличивается: в 2013 г. - 1 работа, в 2015 г. 2, 2016 - 3, 2017 - 4, за первые 8 месяцев 2018 г. - 5 .

В табл. 1 приведены структурные характеристики всех использованных электрохромных устройств.

В табл. 2 обобщены результаты по оптическим спектральным свойствам, циклической стабильности и длительности переходных процессов.

Результаты в табл. 1,2 приведены строго в хронологической последовательности публикации содержащих их работ. Это дает возможность проследить тенденцию применения новых материалов и изменения оптических и других свойств исследованных устройств. Впервые примененные материалы и наиболее значительные результаты выделены жирным шрифтом.

В структурной формуле элементы указаны в направлении проходящего излучения. Следует отметить, что в большинстве случаев (10 из 15) исследования были выполнены с использованием более простых электрохромных ячеек с тремя электродами. В таком устройстве электрохромный слой на стекле с ITO покрытием в качестве рабочего электрода помещается в стеклянную кювету с электролитом, контрэлектрод - фольга или

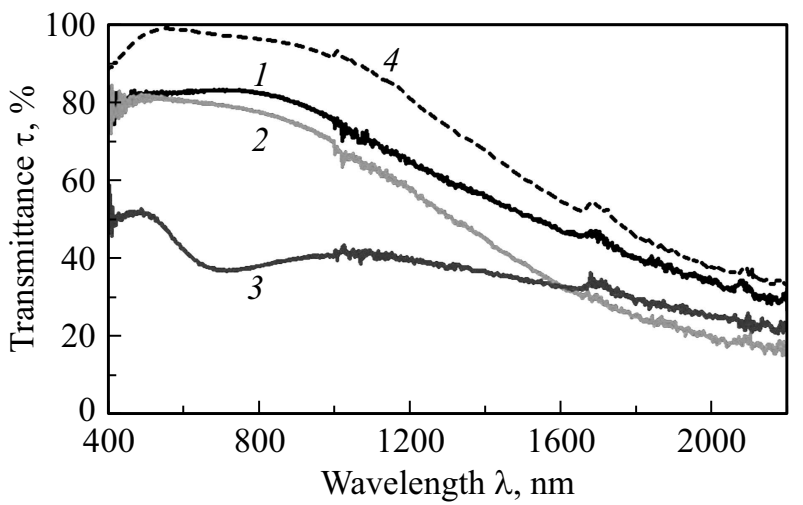

Рис. 6. Спектры пропускания электрохромной ячейки с наноструктурным однокомпонентным $\mathrm{TiO}_{2}: \mathrm{Nb}-8 \%$ электродом в трех оптических состояниях при значении потенциала электрода [24]: 3.5 (1), 1.8 (2), $1.5 \mathrm{~V}$ (3); 4 - спектр пропускания стекла с ITO покрытием.

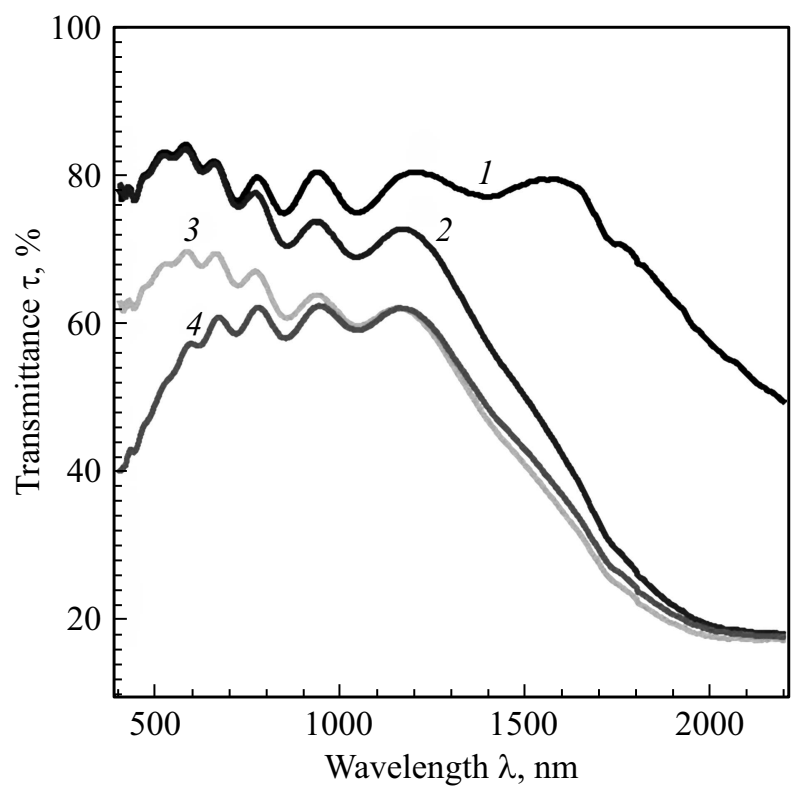

Рис. 7. Спектры пропускания электрохромного стекла с однослойным двухкомпонентным наноструктурным ITO $+\mathrm{NbO}_{x}$ электродом при значениях потенциала на катоде [15]: $+2.0 \mathrm{~V}(1),-0.2 \mathrm{~V}(2),-1.5 \mathrm{~V}(3),-2.5 \mathrm{~V}(4)$.

проволока из лития или платины. Третий электрод базовый, с фиксированным потенциалом, относительно которого отсчитывается потенциал рабочего электрода. Этот электрод изготовлен в виде фольги или проволоки, вид материала которых указан в табл. 1. В электрохромных ячейках с тремя электродами не требуется герметизация и отсутствует стекло на тыльной стороне, поэтому коэффициенты пропускания для таких ячеек примерно на 15-25\% больше, чем для аналогичных образцов с тыльным стеклом [15,23]. Образцы электрохромных стекол с использованием второго стекла с ITO покрытием исследованы в работах [15-17,19,23]. 
Таблица 1. Характеристики электрохромных электродов и электролитов в электрохимических ячейках и стеклах с независимым регулированием пропускания видимого света и БИК излучения. Характеристики устройств указаны в хронологической последовательности публикации работ, содержащих их описание.

\begin{tabular}{|c|c|c|c|c|c|c|c|c|c|}
\hline \multirow[b]{2}{*}{$\begin{array}{r}\text { № } \\
\text { п.П. }\end{array}$} & \multicolumn{3}{|c|}{ Характеристики наночастиц электрода } & \multirow[b]{2}{*}{$\delta, \mathrm{nm}$} & \multirow[b]{2}{*}{$\mathrm{N}$} & \multirow[b]{2}{*}{ 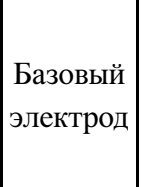 } & \multirow[b]{2}{*}{ Электролит } & \multirow{2}{*}{$\begin{array}{c}\text { Структурная } \\
\text { формула } \\
\text { электрохромного } \\
\text { устройства }\end{array}$} & \multirow[b]{2}{*}{ Лит-ра } \\
\hline & $\begin{array}{l}\text { Электро- } \\
\text { хромный } \\
\text { материал }\end{array}$ & Форма наночастиц & $\begin{array}{c}\text { Средний } \\
\text { размер, } \\
\text { nm }\end{array}$ & & & & & & \\
\hline 1 & $\mathbf{I T O}+\mathbf{N b O}_{x}$ & \begin{tabular}{|c|} 
ITO - нано- \\
кристаллы $-12 \% \mathrm{Sn}$, \\
NbO $_{x}-$ аморфная \\
матрица-стекло
\end{tabular} & 4.8 & 150 & 3 & $\mathrm{Li}$ & $0.1 \mathrm{M} \mathrm{LiClO}_{4} \mathrm{PC}$ & $\begin{array}{c}\text { стекло/ITO } \\
/ \mathrm{ITO}+\mathrm{NbO}_{x} / Э Л / \mathrm{Li}\end{array}$ & {$[13]$} \\
\hline 2 & $\mathbf{W O}_{3-x}+\mathbf{N b O}_{x}$ & $\begin{array}{c}\mathbf{W O}_{3-x}-\text { нано- } \\
\text { кристаллы, } \\
\mathrm{NbO}_{x}-\text { аморфная } \\
\text { матрица-стекло }\end{array}$ & $\sim 4.3$ & 260 & 3 & $\mathrm{Li}$ & $0.1 \mathrm{M}$ Li-TFSI TG & $\begin{array}{c}\text { стекло/ITO } \\
/ \mathrm{WO}_{3-x}+\mathrm{NbO}_{x} / \text { ЭЛ/Li }\end{array}$ & {$[14]$} \\
\hline 3 & $\mathrm{TiO}_{2}: \mathbf{N b}$ & $\begin{array}{c}\text { Нанокристаллы - } \\
8 \% \mathrm{Nb}\end{array}$ & 11 & 140 & 3 & $\mathrm{Li}$ & $0.1 \mathrm{M}$ Li-TFSI TG & $\begin{array}{c}\text { стекло/ITO } \\
/ \mathrm{TiO}_{2}: \mathrm{Nb} / Э Л / \mathrm{Li}\end{array}$ & {$[24]$} \\
\hline 4 & ITO + PT & $\begin{array}{c}\text { ITO - нано- } \\
\text { кристаллы - 13\% Sn, } \\
\text { РТ - полимер } \\
\text { политиофен }\end{array}$ & $\sim 5$ & 400 & 3 & $\mathrm{Ag}$ & 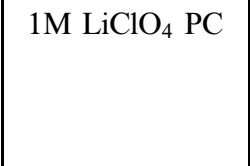 & $\begin{array}{c}\text { стекло/ITO } \\
/ \mathrm{ITO}+\mathrm{PT} / Э Л / \mathrm{Pt}\end{array}$ & {$[25]$} \\
\hline \multirow[t]{2}{*}{5} & \multirow[t]{2}{*}{$\mathbf{I T O}+\mathbf{N b O}_{x}$} & \multirow{2}{*}{$\begin{array}{c}\text { ITO - нано- } \\
\text { кристаллы, } \\
\text { NbO }_{x}-\text { связанная } \\
\text { матрица-стекло } \\
\end{array}$} & $\sim 5$ & 300 & 3 & $\mathrm{Li}$ & $0.1 \mathrm{M}$ Li-TFSI TG & $\begin{array}{c}\text { стекло/FTO } \\
/ \mathrm{ITO}+\mathrm{NbO}_{x} / \text { ЭЛ/Li }\end{array}$ & \multirow[t]{2}{*}[15]{} \\
\hline & & & $\sim 5$ & 300 & 2 & - & ЭЛ5 & $\begin{array}{c}\text { стекло/FTO/ITO+NbO } / \\
\text { ЭЛ5/CeO } / \text { } / \mathrm{FTO} / \text { стекло }\end{array}$ & \\
\hline 6 & $\mathbf{W O}_{3-x}$ & Наностержни & $60 / 3$ & 1200 & 2 & - & ЭЛ6 & $\begin{array}{l}\text { стекло/ITO/ } \mathrm{WO}_{3-x} \\
\text { /ЭЛ6/Pt/ITO/стекло }\end{array}$ & {$[16]$} \\
\hline 7 & $\mathrm{TiO}_{2}: \mathrm{Nb}$ & $\begin{array}{c}\text { Нанокристаллы - } \\
10 \% \mathrm{Nb}\end{array}$ & $\sim 10$ & 2100 & 2 & - & ЭЛ7 & $\begin{array}{l}\text { стекло/ITO/TiO } 2: \mathrm{Nb} \\
\text { /ЭЛ7/Pt/ITO/стекло }\end{array}$ & {$[17]$} \\
\hline 8 & $\begin{array}{c}\mathrm{W}_{18} \mathrm{O}_{49} \\
/ \mathrm{KFe}\left[\mathrm{Fe}(\mathrm{CN})_{6}\right]\end{array}$ & Нанопроволока & - & $\begin{array}{l}700 \\
1300\end{array}$ & 3 & $\begin{array}{c}\mathrm{Ag} \\
/ \mathrm{AgCl}\end{array}$ & $1 \mathrm{M} \mathrm{LiClO}_{4} \mathrm{PC}$ & $\begin{array}{l}\text { стекло/FTO/W }{ }_{18} \mathrm{O}_{49} \\
/ \mathrm{KFe}\left[\mathrm{Fe}(\mathrm{CN})_{6}\right] / Э Л / \mathrm{Pt}\end{array}$ & {$[20]$} \\
\hline 9 & $\mathrm{WO}_{3-x}+\mathrm{NbO}_{x}$ & $\begin{array}{c}\mathrm{WO}_{3-x}- \\
\text { наностержни, } \\
\mathrm{NbO}_{x} \text { - аморфная } \\
\text { матрица-стекло }\end{array}$ & $\begin{array}{l}30 / 4.3 ; \\
85 / 5.3\end{array}$ & 300 & 3 & $\mathrm{Li}$ & $1 \mathrm{M}$ Li-TFSI TG & $\begin{array}{c}\text { PET/ITO } \\
/ \mathrm{WO}_{3-x}+\mathrm{NbO}_{x} / \text { ЭЛ/Li }\end{array}$ & {$[26]$} \\
\hline \multirow[t]{2}{*}{10} & \multirow[t]{2}{*}{$\mathbf{W O}_{3-x}$} & $\begin{array}{c}\text { Tрубчатые } \\
\text { вырезанные } \\
\text { наностержни } \\
\end{array}$ & $\begin{array}{c}80 / \\
(2.5-7.5)\end{array}$ & 1200 & \multirow[t]{2}{*}{3} & \multirow[t]{2}{*}{$\begin{array}{c}\mathrm{Ag} \\
/ \mathrm{AgCl}\end{array}$} & \multirow[t]{2}{*}{$1 \mathrm{M} \mathrm{LiClO}_{4} \mathrm{PC}$} & \multirow[t]{2}{*}{$\begin{array}{c}\text { стекло/ITO } \\
/ \mathrm{WO}_{3-x} / \text { ЭЛ/Pt }\end{array}$} & \multirow[t]{2}{*}[18]{} \\
\hline & & $\begin{array}{l}\text { Наностержни } \\
\text { сплошные }\end{array}$ & $80 / 3$ & 1200 & & & & & \\
\hline 11 & $\mathrm{~W}_{18} \mathrm{O}_{49} / \mathrm{P}_{8} \mathrm{~W}_{48}$ & $\begin{array}{c}\mathrm{W}_{18} \mathrm{O}_{49}-\text { нано- } \\
\text { проволока, } \\
\mathrm{P}_{8} \mathrm{~W}_{48}- \\
\text { корончатые }\end{array}$ & $2000 / 15$ & - & 3 & $\begin{array}{c}\mathrm{Ag} \\
/ \mathrm{AgCl}\end{array}$ & $0.1 \mathrm{M} \mathrm{LiClO}_{4}$ & $\begin{array}{c}\text { стекло/ITO/ } \mathrm{W}_{18} \mathrm{O}_{49} \\
/ \mathrm{P}_{8} \mathrm{~W}_{48} / \text { ЭЛ/Pt }\end{array}$ & {$[21]$} \\
\hline 12 & $\mathrm{WO}_{3-x}$ & Нанопроволока & $30 / 2.5$ & 450 & 3 & $\mathrm{Li}$ & $0.5 \mathrm{M}$ Li-TFSI TG & стекло/ITO/WO $\mathrm{WO}_{3-x} / Э Л / \mathrm{Li}$ & {$[4]$} \\
\hline 13 & $\mathrm{WO}_{3} / \mathrm{TiO}_{2}: \mathrm{V}$ & $\begin{array}{c}\mathrm{WO}_{3} \text { - нано- } \\
\text { кристаллы, } \\
\mathrm{TiO}_{2}: \mathrm{V} \text { - нано- } \\
\text { кристаллы }\end{array}$ & $10 / 5$ & $600 / 700$ & 2 & - & ЭЛ13 & $\begin{array}{c}\text { стекло/ITO/WO } \mathrm{WO}_{3-x} \\
/ \text { ЭЛ13/TiO } 2: \mathrm{V} / \mathrm{ITO} / \text { стекло }\end{array}$ & [19] \\
\hline
\end{tabular}


Таблица 1 (продолжение).

\begin{tabular}{|c|c|c|c|c|c|c|c|c|c|}
\hline \multirow[b]{2}{*}{$\begin{array}{c}\text { № } \\
\text { П.П. }\end{array}$} & \multicolumn{3}{|c|}{ Характеристики наночастиц электрода } & \multirow[b]{2}{*}{$\delta, \mathrm{nm}$} & \multirow[b]{2}{*}{$\mathrm{N}$} & \multirow[b]{2}{*}{$\begin{array}{l}\text { Базовый } \\
\text { электрод }\end{array}$} & \multirow[b]{2}{*}{ Электролит } & \multirow{2}{*}{$\begin{array}{c}\text { Структурная } \\
\text { формула } \\
\text { электрохромного } \\
\text { устройства }\end{array}$} & \multirow[b]{2}{*}{ Лит-ра } \\
\hline & $\begin{array}{l}\text { Электро- } \\
\text { хромный } \\
\text { материал }\end{array}$ & Форма наночастиц & $\begin{array}{c}\text { Средний } \\
\text { размер, } \\
\text { nm }\end{array}$ & & & & & & \\
\hline 14 & $\mathrm{TiO}_{2}: \mathrm{Ta}$ & $\begin{array}{c}\text { Нанокристаллы - } \\
13 \% \text { Та }\end{array}$ & 11.6 & 1200 & 3 & $\mathrm{Li}$ & $0.5 \mathrm{M}$ Li-TFSI TG & 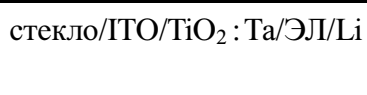 & {$[22]$} \\
\hline \multirow[t]{2}{*}{15} & \multirow[t]{2}{*}{$\mathrm{WO}_{3-x}$} & \multirow[t]{2}{*}{ Нанопроволока } & $30 / 2.5$ & 455 & 3 & $\mathrm{Ag} / \mathrm{Ag}^{+}$ & $1 \mathrm{MAl}\left(\mathrm{ClO}_{4}\right)_{3} \mathrm{PC}$ & стекло/ITO/ $\mathrm{WO}_{3-x} /$ ЭЛ/Pt & \multirow[t]{2}{*}[23]{} \\
\hline & & & $30 / 2.5$ & 455 & 2 & - & $1 \mathrm{MAl}\left(\mathrm{ClO}_{4}\right)_{3} \mathrm{PC}$ & 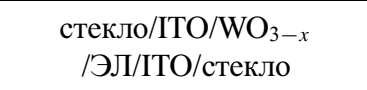 & \\
\hline
\end{tabular}

Примечание. $\delta$ - толщина наноструктурного электрохромного электрода, $\mathrm{nm} ; N$ - количество электродов в электрохромном устройстве. Цифра 2 - электрохромное стекло, цифра 3 - электрохромная ячейка с 3 электродами без тыльного стекла, 3-й электрод - базовый с фиксированным потенциалом;

- в структурной формуле элементы указаны в направлении проходящего излучения;

- впервые примененные материалы выделены жирным шрифтом;

- $1 \mathrm{M} \mathrm{LiClO}_{4} \mathrm{PC}-1 \mathrm{M} \mathrm{LiClO}_{4}$ в пропиленкарбонате,

- Li-TFSI TG - трифлюорометансульфонимид в тетраглиме;

- ЭЛ5 - полимерный гель электролит - электролит в полиметилметакрилате и в тетраглиме;

- ЭЛ6 - 0.7 $\mathrm{M} \mathrm{LiClO}_{4}+0.3 \mathrm{M} \mathrm{LiI} \mathrm{в} \mathrm{пропиленкарбонате-ацетонитриле} \mathrm{(70/30);}$

- ЭЛ7 - $1 \mathrm{M} \mathrm{LiClO}_{4}+0.1 \mathrm{M} \mathrm{LiI} \mathrm{в} \mathrm{диметилсульфоксиде;}$

- РЕТ - пленка из полиэтилентерефталата; $\mathrm{KFe}\left[\mathrm{Fe}(\mathrm{CN})_{6}\right]$ — „прусский голубой“;

- ЭЛ13 - $1 \mathrm{M} \mathrm{LiClO}_{4}+0.05 \mathrm{M} \mathrm{LiI} \mathrm{в} \mathrm{диметилсульфоксиде.}$

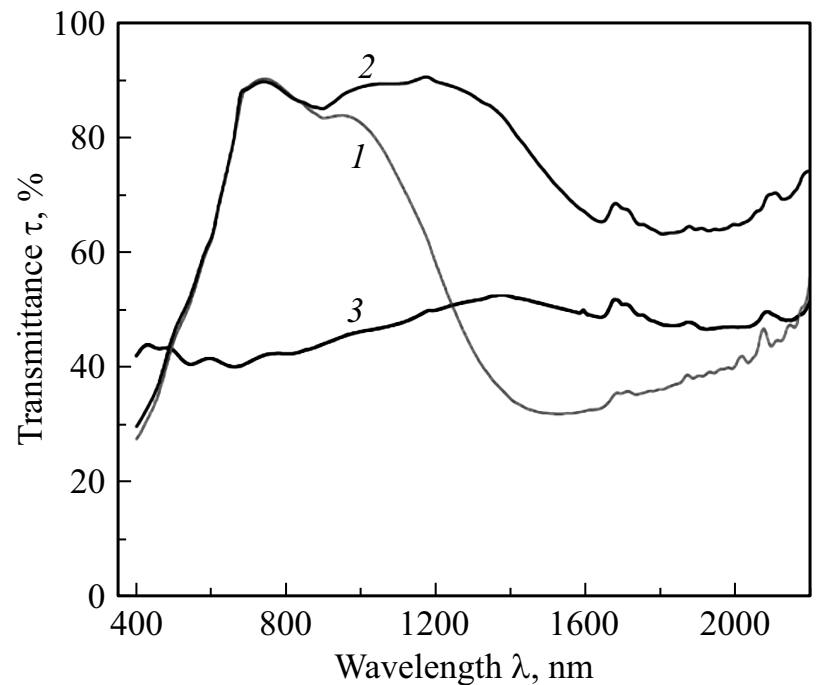

Рис. 8. Спектры пропускания (относительно стекла с покрытием ITO) электрохромной ячейки с гибридным электродом, содержащим диспергированные в полимерной матрице из политиофена нанокристаллы ITO, в трех оптических состояниях при значении потенциала электрода $[25]:-1.25 \mathrm{~V}-$ светлое холодное состояние (1); 0.625 - светлое теплое (2); $1.25 \mathrm{~V}$ темное холодное (3).

В табл. 2 приведены данные по величине модуляции коэффициентов пропускания $\Delta \tau$. Модуляция (изменение) коэффициента пропускания $\Delta \tau=\tau^{\circ}-\tau^{\bullet}$ рассчитывается как разность между его максимальным $\tau^{\circ}$ в светлом теплом и минимальным $\tau^{\bullet}$ в темном холодном состояниях значениями. Эти величины определены как для усредненных значений коэффициентов пропускания для диапазона видимого света $\tau_{\text {vis }}$, БИК излучения $\tau_{\mathrm{NIR}}$ и всего солнечного света $\tau_{s}$, так и для локальных величин $\tau$. Для локальных коэффициентов пропускания значения $\Delta \tau_{550}$ выбраны для середины диапазона видимого света (максимальная его интенсивность), $\Delta \tau_{800}-$ для границы между видимым светом и БИК излучением, $\Delta \tau_{1200}$ - примерно для середины диапазона БИК излучения. Значения модуляции усредненных коэффициентов пропускания приведены только в половине (7 из 15) всех работ. Величины модуляции локальных коэффициентов

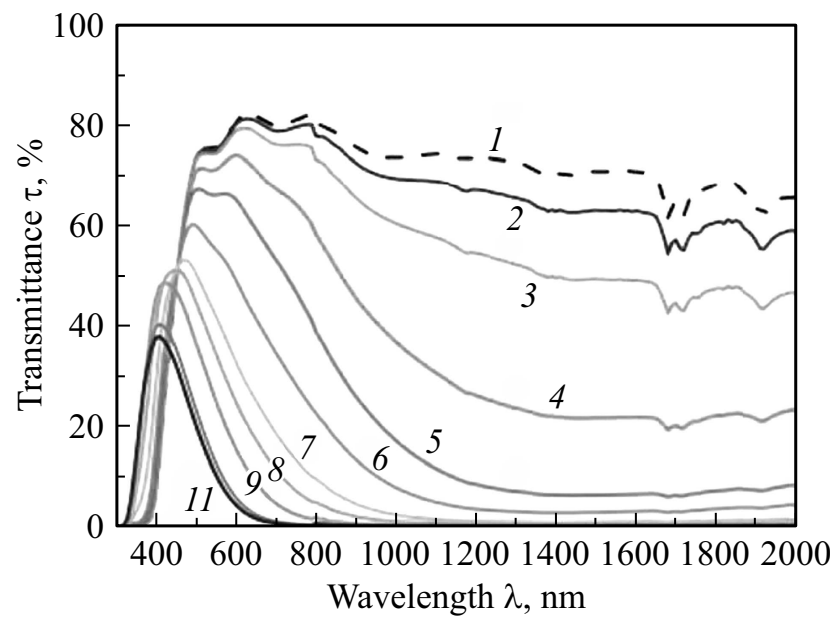

Рис. 9. Спектры пропускания электрохромного стекла с однокомпонентным наноструктурным $\mathrm{WO}_{3-x}$ электродом при напряжении на стекле от 0 до $-1.8 \mathrm{~V}[16]: 0 \mathrm{~V}(1),-0.1$ (2), $-0.2(3),-0.3(4),-0.4(5),-0.5(6),-0.6(7),-0.7(8)$, $-1.0(9),-1.5(10),-1.8 \mathrm{~V}(11)$. 
Таблица 2. Оптические характеристики электрохромных ячеек-стекол с независимым регулированием пропускания видимого света и ближнего инфракрасного излучения. Результаты приведены в хронологической последовательности.

\begin{tabular}{|c|c|c|c|c|c|c|c|c|c|c|c|}
\hline №п.п. & Электрохромный материал & $\Delta \tau_{\text {vis }}$ & $\Delta \tau_{\mathrm{NIR}}$ & $\Delta \tau_{s}$ & $\Delta \tau_{550}$ & $\Delta \tau_{800}$ & $\Delta \tau_{1200}$ & $t_{c} / t_{b}, \mathrm{~s}$ & $n$ & Циклическая стабильность & Лит-ра \\
\hline 1 & $\mathrm{ITO}+\mathrm{NbO}_{x}$ & - & - & - & $\sim 38$ & $\sim 21$ & $\sim 17$ & - & 3 & $2000(4 \%)$ & [13] \\
\hline 2 & $\mathrm{WO}_{3-x}+\mathrm{NbO}_{x}$ & 71 & 84 & 78 & $\sim 71$ & $\sim 90$ & $\sim 88$ & - & 3 & $2000(5.7 \%)$ & {$[14]$} \\
\hline 3 & $\mathrm{TiO}_{2}: \mathrm{Nb}$ & - & - & - & $\sim 34$ & $\sim 44$ & $\sim 26$ & - & 3 & - & {$[24]$} \\
\hline 4 & $\mathrm{ITO}+\mathrm{PT}$ & - & - & - & $\sim 9$ & $\sim 45$ & $\sim 40$ & $68 / 19$ & 3 & $200(18 \%)$ & {$[25]$} \\
\hline \multirow[t]{3}{*}{5} & $\mathrm{ITO}+\mathrm{NbO}_{x}$-ячейка & - & - & - & $\sim 39$ & $\sim 31$ & $\sim 34$ & - & 3 & $1000(5 \%)$ & \multirow[t]{3}{*}[15]{} \\
\hline & $\mathrm{ITO}+\mathrm{NbO}_{x}$-стекло & - & - & - & $\sim 29$ & $\sim 18$ & $\sim 19$ & - & 3 & - & \\
\hline & \multicolumn{10}{|c|}{ Электрохромное стекло с полимерным гель-электролитом } & \\
\hline 6 & $\mathrm{WO}_{3-x}$-стекло & $\sim 67$ & $\sim 72$ & $\sim 68$ & $\sim 68$ & $\sim 82$ & $\sim 72$ & - & 3 & - & {$[16]$} \\
\hline 7 & $\mathrm{TiO}_{2}: \mathrm{Nb}-$ стекло & $\sim 72$ & $\sim 73$ & $\sim 65$ & $\sim 75$ & $\sim 72$ & $\sim 60$ & $105 / 10$ & 3 & 200 & {$[17]$} \\
\hline 8 & $\mathrm{~W}_{18} \mathrm{O}_{49} / \mathrm{KFe}\left[\mathrm{Fe}(\mathrm{CN})_{6}\right]$ & - & - & - & $\sim 48$ & $\sim 78$ & $\sim 51$ & $2.2 / 4.2$ & 4 & $100(30 \%)$ & [20] \\
\hline \multirow[t]{2}{*}{9} & $\mathrm{WO}_{3-x}+\mathrm{NbO}_{x}$ & - & - & - & $\sim 79$ & $\sim 76$ & $\sim 63$ & - & 3 & 2500 & \multirow[t]{2}{*}[26]{} \\
\hline & \multicolumn{10}{|c|}{ Гибкая электрохромная ячейка на полимерной пленке из полиэтилентерефталата } & \\
\hline \multirow[t]{2}{*}{10} & \multirow[t]{2}{*}{$\mathrm{WO}_{3-x}$} & 47 & 81 & 59 & $\sim 42$ & $\sim 80$ & 79 & $12 / 12$ & 3 & - & \multirow[t]{2}{*}[18]{} \\
\hline & & 73 & 93 & 76 & $\sim 72$ & $\sim 94$ & 89 & $98 />1200$ & 3 & - & \\
\hline 11 & $\mathrm{~W}_{18} \mathrm{O}_{49} / \mathrm{P}_{8} \mathrm{~W}_{48}$ & 51 & 66 & 62 & $\sim 67$ & $\sim 72$ & $\sim 64$ & $26 / 86$ & 3 & $500(2.4 / \%)$ & {$[21]$} \\
\hline 12 & $\mathrm{WO}_{3-x}$ & 83.2 & 92.8 & 91.4 & $\sim 85$ & 92.7 & 94.6 & $21 / 85$ & 3 & $1000(8.3 \%)$ & {$[4]$} \\
\hline 13 & $\mathrm{WO}_{3} / \mathrm{TiO}_{2}: \mathrm{V}$-стекло & - & - & - & $\sim 56$ & $\sim 73$ & $\sim 74$ & - & 4 & - & [19] \\
\hline 14 & $\mathrm{TiO}_{2}: \mathrm{Ta}$ & - & - & - & 86.3 & $\sim 93.5$ & $\sim 85$ & $67 / 7$ & 3 & $2000(1.3 \%)$ & {$[22]$} \\
\hline \multirow[t]{2}{*}{15} & $\mathrm{WO}_{3-x}$-ячейка & 82.3 & 88.8 & 84.7 & 89.3 & 91.7 & 88.5 & $16 / 13$ & 3 & $2000(7.6 \%)$ & \multirow[t]{2}{*}[23]{} \\
\hline & $\mathrm{WO}_{3-x}$-стекло & - & - & - & $|\sim 69|$ & $\sim 73$ & \begin{tabular}{|l|}
70 \\
\end{tabular} & - & 3 & - & \\
\hline
\end{tabular}

Примечание. $t_{c} / t_{b}$ - соотношение между временем $t_{c}$ перехода в затемненное состояние из прозрачного и временем $t_{b}$ обратного перехода в прозрачное состояние из затемненного в диапазоне видимого света при циклических переключениях, s; $n-$ количество оптических состояний; циклическая стабильность - количество выполненных циклических переключений и снижение модуляции $\Delta \tau$ коэффициента пропускания в диапазоне видимого света после них (в скобках); наиболее значительные результаты выделены жирным шрифтом;

$\Delta \tau_{\mathrm{vis}}=\tau_{\mathrm{vis}}^{\circ}-\tau_{\mathrm{vis}}^{\bullet} ; \Delta \tau_{\mathrm{NIR}}=\tau_{\mathrm{NIR}}^{\circ}-\tau_{\mathrm{NIR}}^{\bullet} ; \Delta \tau_{\mathrm{s}}=\tau_{\mathrm{s}}^{\circ}-\tau_{\mathrm{s}}^{\bullet}$, где $\tau^{\circ}, \tau^{\bullet}-$ усредненные коэффициенты пропускания в светлом и темном состояниях для соответствующих участков солнечного спектра соответственно, \%;

$\Delta \tau_{550}=\tau_{550}^{\circ}-\tau_{550}^{\bullet}-$ изменение (модуляция) коэффициента пропускания при переходе из светлого в темное состояние при длине волны излучения $550 \mathrm{~nm}$. Приближенные величины (со знаком ) определены на основании имеющихся в опубликованных работах графиков спектральных коэффициентов пропускания.

пропускания не приведены практически ни в одной работе, за исключением [22,23].

На рис. 4-18 приведены спектральные характеристики всех исследованных электрохромных устройств, причем также в хронологической последовательности.

Все указанные в табл. 2 значения $\Delta \tau_{550}, \Delta \tau_{800}, \Delta \tau_{1200}$ определены приближенно графически с использованием в увеличенном виде приведенных на рис. 4-18 результатов. На это указывает значок $(\sim)$, например $\sim 72$.

Однослойные однокомпонентные электрохромные электроды. Основные усилия во всех исследованиях направлены на отладку более простой технологии изготовления мезопористых наноструктурных электро- дов. Это достигается для однокомпонентных электродов, при изготовлении которых коллоидный раствор с нанокристаллами наносят тонким слоем на стекло со слоем прозрачного электропроводящего материала (ITO или FTO). Затем пленку подвергают сушке-отжигу в потоке нагретого до $400-430^{\circ} \mathrm{C}$ воздуха.

Во всех работах, за исключением $[14,19]$, наночастицы $\mathrm{W}_{18} \mathrm{O}_{49}\left(\mathrm{WO}_{2.72}\right)$ имеют продолговатую форму стержней или волокон и образуют при сушке проницаемую для электролита регулярную матрицу типа войлока. При этом легированные кислородными вакансиями наночастицы $\mathrm{W}_{18} \mathrm{O}_{49}$ окисляются до почти стехиометрического состава $\mathrm{WO}_{3-x}$. 


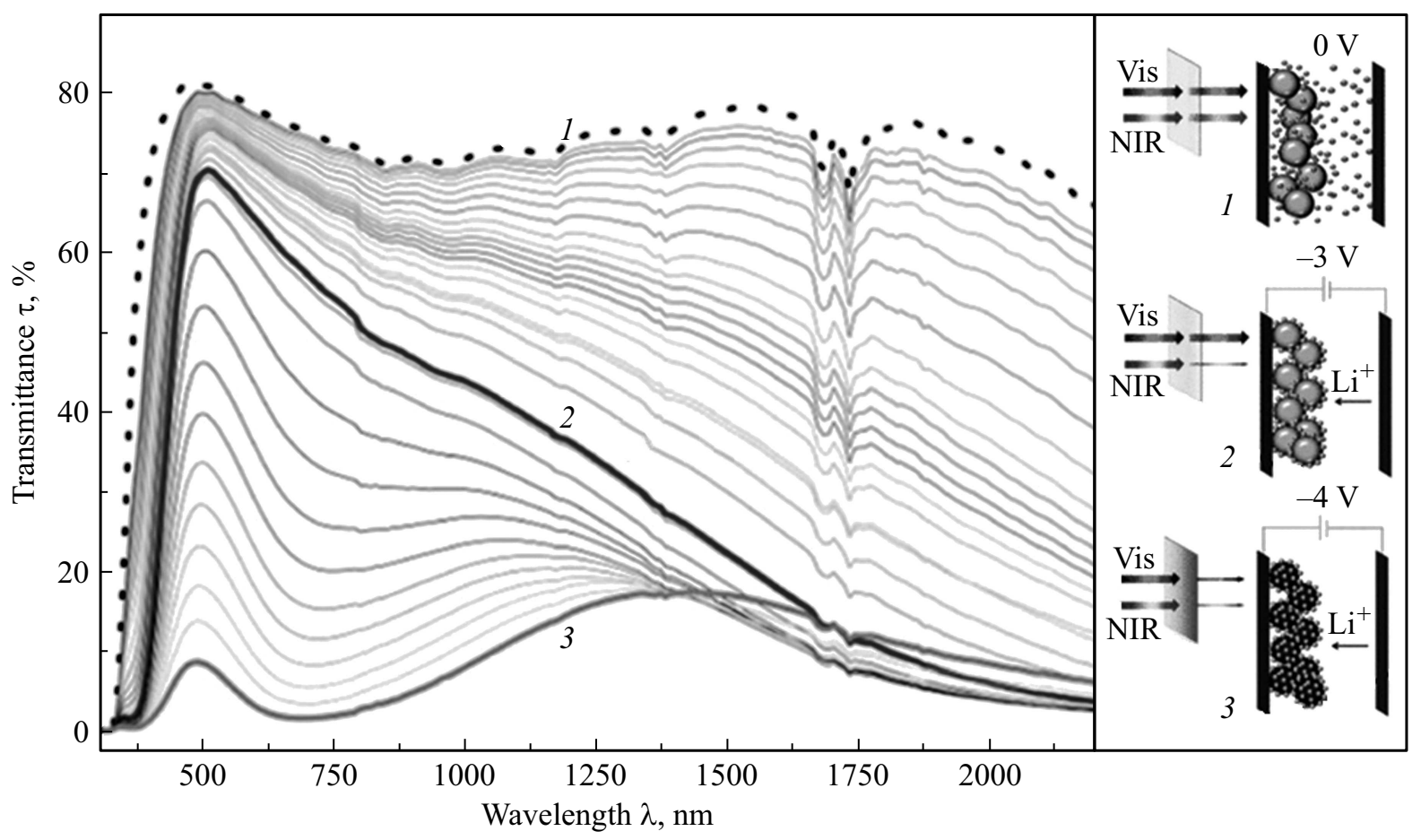

Рис. 10. Спектры пропускания электрохромного стекла с однокомпонентным наноструктурным $\mathrm{TiO}_{2}: \mathrm{Nb}^{-10 \%}$ электродом при напряжении на стекле [17]: 0 (1), -3 (2), $-4 \mathrm{~V}(3)$.
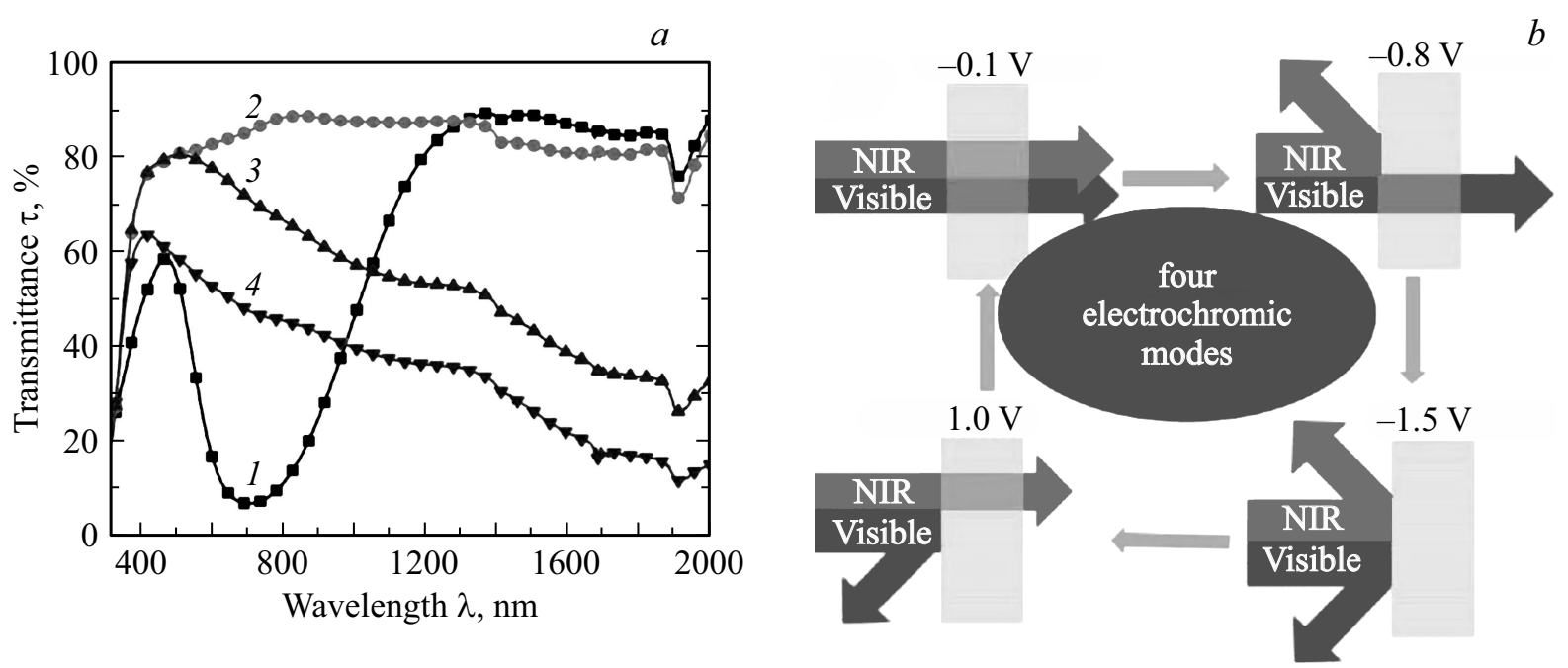

Рис. 11. Свойства электрохромной ячейки с двухслойным наноструктурным $\mathrm{W}_{18} \mathrm{O}_{49} / \mathrm{KFe}\left[\mathrm{Fe}(\mathrm{CN})_{6}\right]$ электродом при различных значениях его потенциала [20]: (a) спектры пропускания электрохромной ячейки в четырех оптических состояниях при значениях потенциала электрода $1.0(1),-0.1(2),-0.8(3),-1.5 \mathrm{~V}(4) ;(b)$ схема четырех оптических состояний ячейки.

В последнее время в качестве материала для изготовления однокомпонентных электрохромных электродов все большее внимание привлекает диоксид титана $\mathrm{TiO}_{2}$. Это вещество доступно, имеет низкую стоимость, химически инертно и термически стабильно, совместимо с другими материалами.

Легирование нанокристаллов $\mathrm{TiO}_{2}$ пяти- или шестивалентными металлами ( $\mathrm{Nb}, \mathrm{Ta}, \mathrm{W}, \mathrm{Mo}$ ) позволяет получать частицы с регулируемой плазмонной резонанс- ной поглощающей способностью. Частота ЛПР таких нанокристаллов зависит от их размера и концентрации легирующего металла. Оптимальная концентрация достигается при соотношении числа атомов диоксида титана и легирующей добавки $\mathrm{M}$, равном $\mathrm{TiO}_{2}: \mathrm{M} \sim 10$. При увеличении валентности легирующего металла возрастает число свободных электронов и уменьшается длина волны максимума ЛПР. Для легированных нанокристаллов $\mathrm{TiO}_{2}$ размером около $8 \mathrm{~nm}$ указанными 


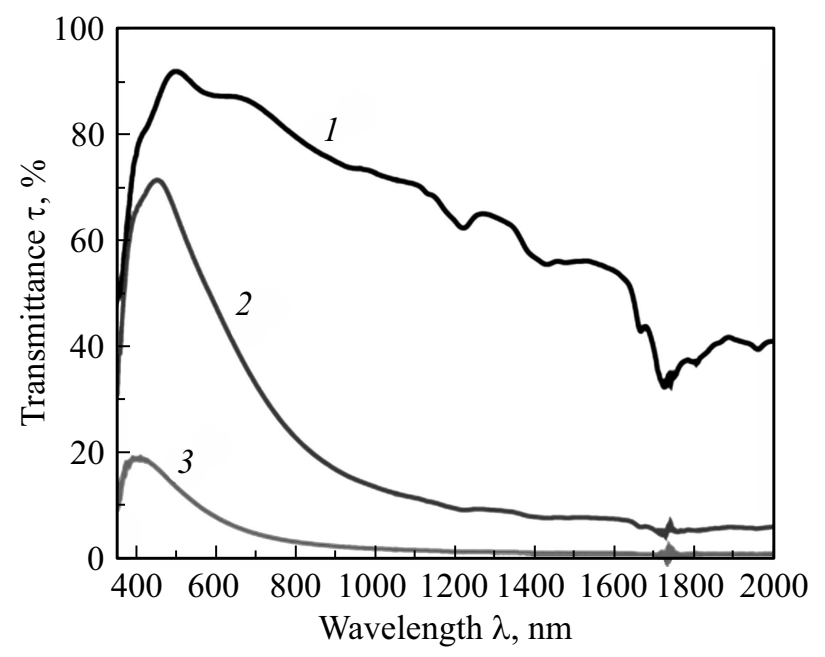

Рис. 12. Спектры пропускания электрохромной ячейки с гибким однослойным двухкомпонентным наноструктурным $\mathrm{WO}_{3-x}+\mathrm{NbO}_{x}$ электродом в трех характерных оптических состояниях при значениях потенциала электрода [26]: 4 (1), $2.4(2), 1.5 \mathrm{~V}(3)$.

выше металлами она равна: для $\mathrm{TiO}_{2}: \mathrm{Mo}-650 \mathrm{~nm}$, $\mathrm{TiO}_{2}: \mathrm{W}-980-1700 \mathrm{~nm}$ в зависимости от концентрации $\mathrm{W}$, для $\mathrm{TiO}_{2}: \mathrm{Nb} \sim 3300 \mathrm{~nm}$ [12]. В табл. 1,2 приведены данные для с изделий с электродами из легированного пятивалентными $\mathrm{Nb}$ и Та диоксида титана $\mathrm{TiO}_{2}[17,22,24]$. Легированный $\mathrm{TiO}_{2}: \mathrm{Nb}$ содержит $\sim 10 \%$ $\mathrm{Nb}, \mathrm{TiO}_{2}: \mathrm{Ta} \sim 13 \%$ Ta.

Из приведенных в табл. 2 данных следует, что все выделенные жирным шрифтом наиболее значительные результаты по оптическим свойствам (модуляции коэффициента пропускания) относятся именно к более простым по изготовлению ячейкам с однокомпонентными электродами из $\mathrm{WO}_{3-x}[4,16,18,23]$ и из легированного диоксида титана $\mathrm{TiO}_{2}: \mathrm{Nb}[17]$ и $\mathrm{TiO}_{2}: \mathrm{Ta}[22]$. Поэтому более подробно остановимся на этих результатах.

\section{Однокомпонентные электрохромные электроды} из $\boldsymbol{W O}_{3-x}$. В табл. 2 и на рис. 9, 13, 15, 18 приведены оптические характеристики устройств с электродами из $\mathrm{WO}_{3-x}$. Зависимости спектральных коэффициентов на рис. $9,13,15,18$ для различных изделий с электродами из $\mathrm{WO}_{3-x}$ практически одинаковы - отличаются лишь численными значениями. Но здесь нужно отметить, что для электрохромных стекол их значения примерно на $20 \%$ меньше, чем для электрохромных ячеек. Это отчетливо видно из сравнения данных на рис. $18, a$ и $18, b$, которые получены для ячейки и стекла с одинаковыми электродами.

Здесь более подробно рассмотрим результаты, приведенные на рис. 15. В начальном состоянии (светлое теплое) ячейка пропускает видимый свет и БИК излучение. При снижении потенциала электрода от 4 до $2.8 \mathrm{~V}$ происходит емкостное накопление заряда наночастиц - электроны накапливаются в их объеме, а ионы
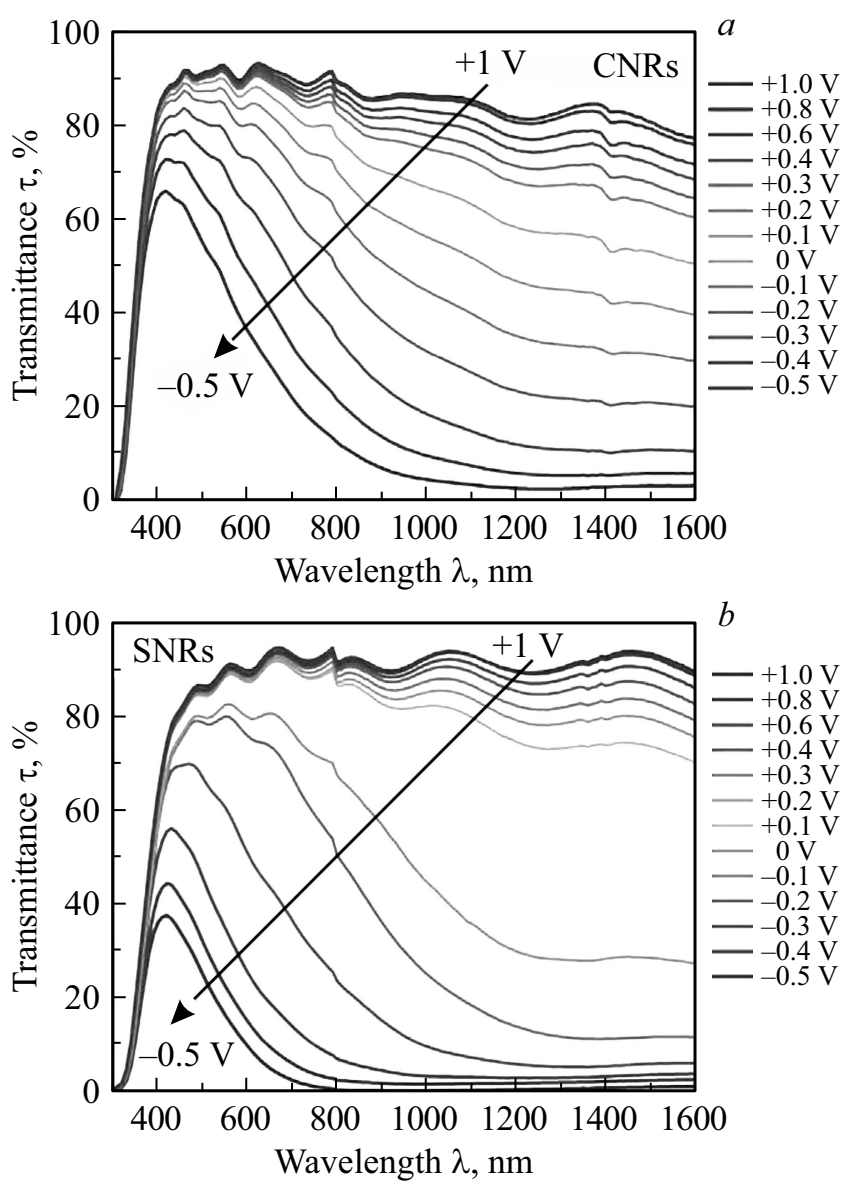

Рис. 13. Спектры пропускания электрохромной ячейки с наноструктурным $\mathrm{WO}_{3-x}$ электродом при его потенциале от +1.0 до $-0.5 \mathrm{~V}[18](1,0.8,0.6,0.4,0.3,0.2,0.1,0,-0.1$, $-0.2,-0.3,-0.4,-0.5 \mathrm{~V}):(a)$ CNRs - трубчатые вырезанные наностержни; (b) SNRs - сплошные наностержни.

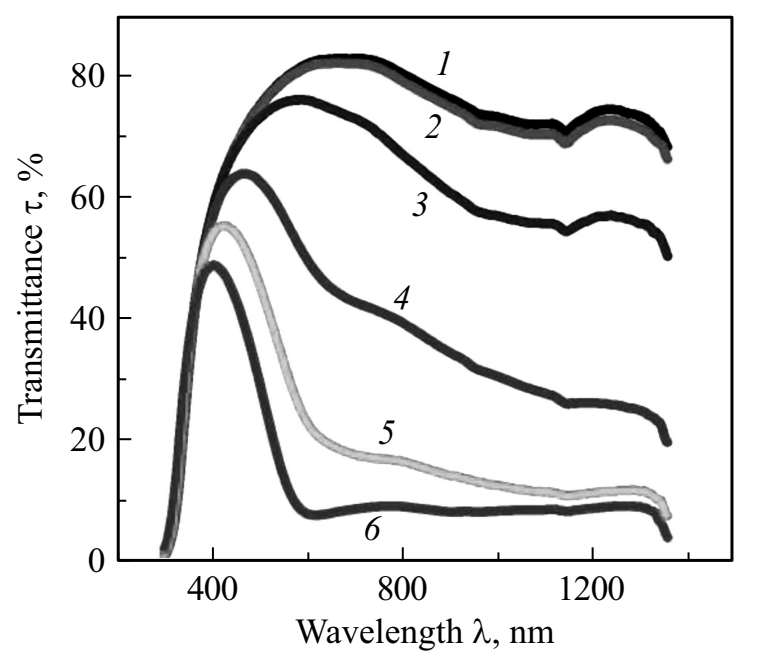

Рис. 14. Спектры пропускания электрохромной ячейки с двухслойным наноструктурным $\mathrm{W}_{18} \mathrm{O}_{49} / \mathrm{P} 8 \mathrm{~W}_{48}$ электродом при его потенциале [21]: $0.4(1), 0.0$ (2), -0.2 (3), -0.6 (4), $-0.8(5),-1.0 \mathrm{~V}(6)$. 


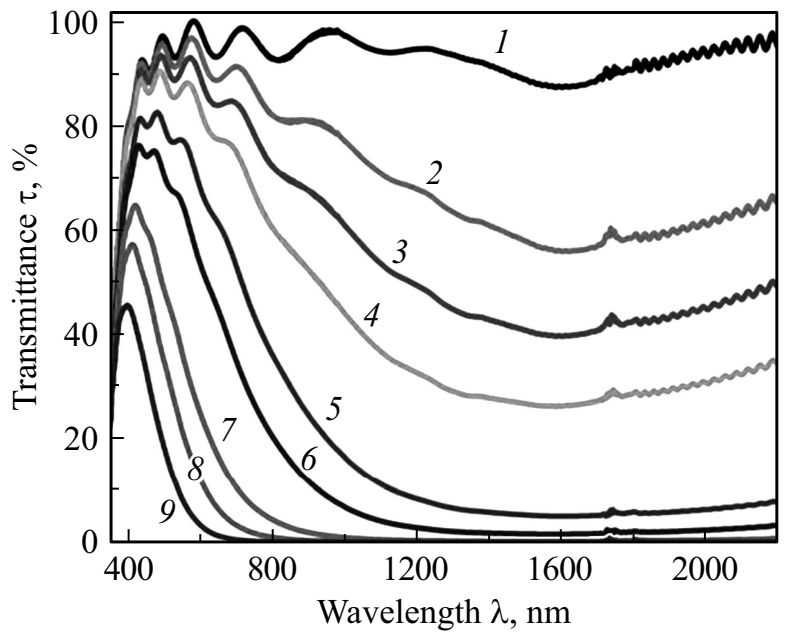

Pис. 15. Спектры пропускания электрохромной ячейки с наноструктурным $\mathrm{WO}_{3-x}$ электродом при его потенциале [4]: 4.0 (1), 3.0 (2), 2.9 (3), 2.8 (4), 2.7 (5), 2.6 (6), 2.4 (7), 2.3 (8), $2.0 \mathrm{~V}(9)$.

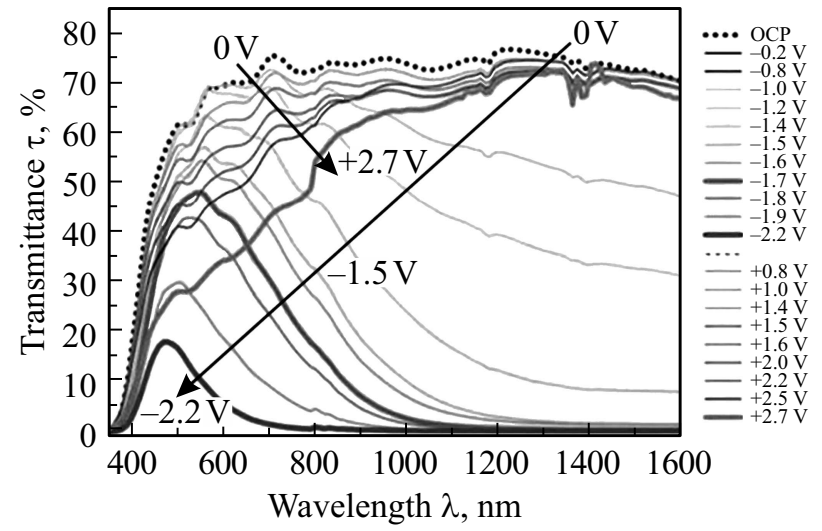

Рис. 16. Спектры пропускания электрохромного стекла с двухслойным наноструктурным $\mathrm{WO}_{3} / \mathrm{TiO}_{2}: \mathrm{V}$ электродом при различных значениях напряжения на стекле [19]. При изменении напряжения от 0 до $-2.2 \mathrm{~V}$ стекло переходит из светлого теплого $(0 \mathrm{~V})$ в светлое холодное $(-1.5 \mathrm{~V})$ и затем в темное холодное $(-2.2 \mathrm{~V})$ состояние. При увеличении напряжения от 0 до $+2.7 \mathrm{~V}$ стекло переходит из светлого теплого в темное теплое состояние.

$\mathrm{Li}^{+}$- на поверхности. При этом постепенно возрастает блокирование БИК излучения вследствие интенсификации плазмонного механизма в результате увеличения концентрации свободных электронов в наночастицах. Максимум полосы поглощения вследствие увеличения частоты локализованного плазмонного резонанса сдвигается влево (голубой сдвиг) и происходит постепенное ослабление проходящего БИК излучения.

В диапазоне $2.8-2.6 \mathrm{~V}$ ионы лития $\mathrm{Li}^{+}$внедряются в кристаллическую структуру, вызывая фазовый переход из моноклинной фазы $\mathrm{WO}_{3-x}$ в тетрагональную фазу литиевой вольфрамовой бронзы $t-\mathrm{Li}_{y} \mathrm{WO}_{3-x}$. Этот фазовый переход сопровождается переходом из состояния диэлек- трика к металлу, что вызывает увеличение отражательной способности в диапазоне БИК излучения. При этом сохраняется плазмонный механизм поглощения БИК излучения вследствие емкостного заряда в результате адсорбции ионов лития $\mathrm{Li}^{+}$на поверхности наночастиц. Таким образом, в диапазоне $2.8-2.6 \mathrm{~V}$ ослабление БИК излучения происходит в результате совместного действия плазмонного механизма и фазового превращения кристаллической структуры. Ослабление видимого света при этом умеренное.

При уменьшении потенциала от 2.6 до $2.0 \mathrm{~V}$ наблюдается значительное снижение пропускания видимого света. В этом режиме в результате продолжающегося внедрения ионов лития $\mathrm{Li}^{+}$кристаллическая тетрагональная структура $t-\mathrm{Li}_{y} \mathrm{WO}_{3-x}$ постепенно перестраивается в кубическую $c-\mathrm{Li}_{y} \mathrm{WO}_{3-x}$. Такая перестройка кристаллической структуры приводит к формированию поляронного механизма поглощения видимого света. При этом сохраняется и плазмонный механизм.

\section{Однокомпонентные электрохромные электроды}

из $\mathrm{TiO}_{2}$. Совместное действие плазмонного и поляронного механизмов ослабления солнечного излучения осуществляется также и в электрохромных устройствах с электродом их нанокристаллов легированного диоксида титана. Результаты исследования электрохромных устройств с электродами из $\mathrm{TiO}_{2}: \mathrm{Nb}(8$ или $10 \% \mathrm{Nb})$ и $\mathrm{TiO}_{2}:$ Та $(13 \%)$ приведены в табл. 1 и 2 и на рис. 6,10 и 17. Результаты для различных электродов практически одинаковы. Дисперсии этих двух видов нанокристаллов в растворителе имеют достаточно близкие между собой длины волн ЛПР около $2500 \mathrm{~nm}$.

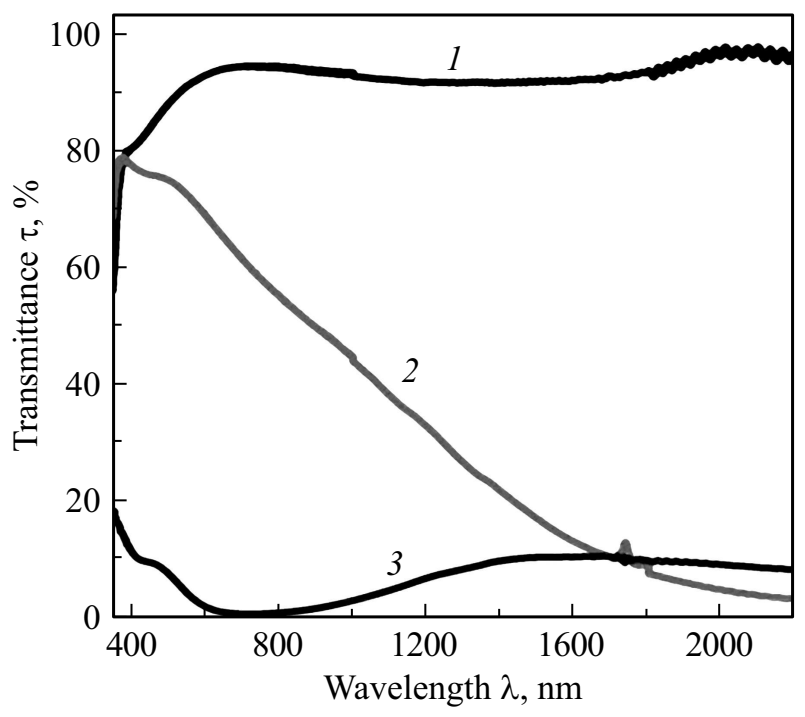

Рис. 17. Спектры пропускания электрохромной ячейки с наноструктурным $\mathrm{TiO}_{2}$ :Та-13\% электродом в характерных оптических состояниях при значении потенциала на электроде [22]: 4.0 (1), $1.8(2), 1.5 \mathrm{~V}(3)$. 


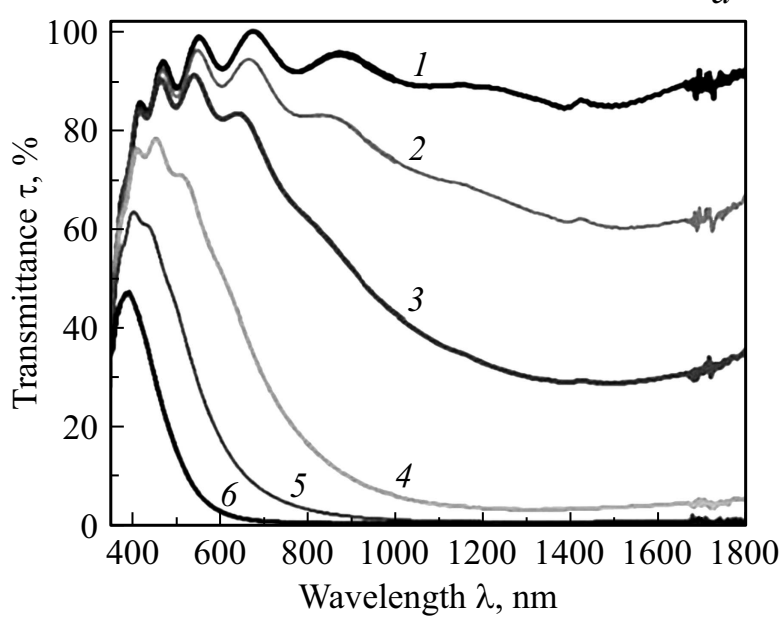

$b$

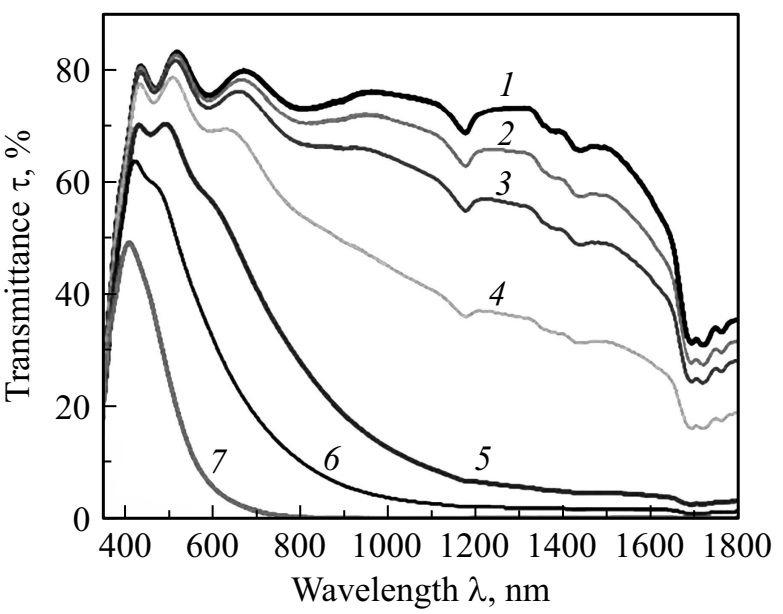

Рис. 18. Спектры пропускания электрохромного устройства с наноструктурным $\mathrm{WO}_{3-x}$ электродом при значениях его потенциала [23] (a) ячейка: $0(1),-0.1(2),-0.3(3),-0.5(4),-0.7(5),-0.9 \mathrm{~V}(6) ;(b)$ стекло: 1.0 (1), 0 (2); -1.0 (3), $-2.0(4),-2.8(5),-3.5(6),-4.0 \mathrm{~V}(7)$.

Более подробные результаты приведены на рис. 10 для электрохромного стекла (не ячейки). Ими и воспользуемся. В правой части рис. 10 схематично изображены три характерных состояния электрохромной ячейки при катодных потенциалах соответственно $0,-3$ и $-4 \mathrm{~V}$. В отключенном состоянии нанокристаллы не имеют электрического заряда и ионы $\mathrm{Li}^{+}$равномерно распределены по объему электролита. При изменении катодного потенциала от 0 до $-3 \mathrm{~V}$ постепенно возрастает концентрация инжектированных электронов в нанокристаллах. Ионы $\mathrm{Li}^{+}$собираются около поверхности нанокристаллов для компенсации их отрицательного заряда, образуя двойной электрический слой. Максимум полосы поглощения вследствие увеличения частоты локализованного плазмонного резонанса сдвигается влево (голубой сдвиг) и происходит постепенное ослабление проходящего БИК излучения. Ослабление видимого света при этом умеренное.

При увеличении отрицательной величины катодного потенциала выше $-3 \mathrm{~V}$ ионы $\mathrm{Li}^{+}$продолжают накапливаться на поверхности нанокристаллов и одновременно начинают постепенно внедряться внутрь их. Это вызывает перестройку кристаллической структуры в ходе фазового перехода от тетрагонального анатаза $\mathrm{TiO}_{2}$ к искаженной орторомбической фазе $\mathrm{Li}_{x} \mathrm{TiO}_{2}$, где $x<0.5$ [24]. Локализация инжектируемых электронов на сайтах $\mathrm{Ti}^{4+}$ приводит к формированию и постепенному повышению интенсивности поляронного механизма поглощения излучения в диапазоне видимого света, при одновременном усилении плазмонного ослабления БИК излучения. При катодном потенциале $-4 \mathrm{~V}$ падающее солнечное излучение почти полностью поглощается во всем диапазоне длин волн. Электрохромная ячейка постепенно переходит из светлого теплого состояния (при
$0 \mathrm{~V})$ к светлому холодному $(-3 \mathrm{~V})$ и далее к темному холодному $(-4 \mathrm{~V})$.

\section{Двухслойные двухкомпонентные электрохром- ные электроды. В табл. 1,2 приведены сведения о} нескольких видах электрохромных ячеек с двухслойными двухкомпонентными электродами [19-21]. Спектральные коэффициенты пропускания изображены соответственно на рис. $11,14,16$. Нужно сразу отметить, что изготовление таких устройств значительно сложнее. Следует выяснить, оправдано ли такое усложнение.

На рис. 14 изображены спектральные коэффициенты пропускания электрохромной ячейки с двухслойным двухкомпонентным электродом с расположенными последовательно наноструктурными слоями $\mathrm{W}_{18} \mathrm{O}_{49}$ и $\mathrm{P}_{8} \mathrm{~W}_{48}$. При изменении потенциала на катоде от 0.4 до $-1.0 \mathrm{~V}$ слой $\mathrm{W}_{18} \mathrm{O}_{49}$ постепенно увеличивает поглощение БИК излучения за счет плазмонного механизма, а слой $\mathrm{P}_{8} \mathrm{~W}_{48}$ также постепенно увеличивает поглощение видимого света.

На основании данных табл. 2 и результатов на рис. 14 , 15 можно заключить, что ячейка с однослойным однокомпонентным электродом из $\mathrm{WO}_{3-x}$ по всем параметрам превосходит ячейку с двухслойным двухкомпонентным электродом из расположенных последовательно наноструктурных слоев $\mathrm{W}_{18} \mathrm{O}_{49}$ и $\mathrm{P}_{8} \mathrm{~W}_{48}$. Добавление второго слоя не дает никакого положительного эффекта, кроме усложнения технологии изготовления.

Достаточно интересные результаты получаются, когда на слой $\mathrm{W}_{18} \mathrm{O}_{49}$ наносится слой „прусского голубого“ [20]. Слой этого вещества обычно используется в качестве анодного слоя - под действием положительного потенциала оно поглощает видимый свет в соответствии с выражением (4). Если слой этого вещества наносится на катодный слой, то под действи- 
ем отрицательного потенциала слой $\mathrm{W}_{18} \mathrm{O}_{49}$ поглощает видимый свет и приобретает голубую окраску, тогда как слой „прусского голубого“ остается прозрачным. При смене полярности потенциала на положительную и увеличении его величины слой $\mathrm{W}_{18} \mathrm{O}_{49}$ становится прозрачным, а слой „прусского голубого“ постепенно увеличивает интенсивность поглощения видимого света и приобретает голубой цвет.

Эти явления находят свое отражение в своеобразном изменении спектрального коэффициента пропускания такой электрохромной ячейки на рис. 11. Ячейка при постепенном уменьшении потенциала катода от +1 до $-1.5 \mathrm{~V}$ последовательно проходит через 4 оптических состояния: темное теплое-светлое теплоесветлое холодное-темное холодное. Однако в состояниях светлое холодное и темное холодное пропускание БИК излучения остается значительным. Слой $\mathrm{W}_{18} \mathrm{O}_{49}$ не достаточно хорошо выполняет задачу ослабления БИК излучения в этих состояниях. По всей видимости, не совсем удачно подобраны форма и размеры наночастиц в этом устройстве.

Четыре оптических состояния реализуются также и в двухслойной электрохимической ячейке, в которой второй электрохромный слой изготовлен из нанонокристаллов модифицированной ванадием двуокиси титана $\mathrm{TiO}_{2}: \mathrm{V}$ и является анодным слоем. При смене полярности потенциала анодного слоя на отрицательную и увеличении его величины слой с возрастающей интенсивностью поглощает видимый свет.

В такой двухслойной ячейке каждый слой независимо активируется в зависимости от знака приложенного потенциала. Катодный нанокристаллический слой $\mathrm{WO}_{3}$ при увеличении отрицательного потенциала последовательно ослабляет сначала БИК излучении, затем видимый свет. При смене полярности и увеличении положительного потенциала на катоде наноструктурный слой $\mathrm{TiO}_{2}: \mathrm{V}$ с возрастающей интенсивностью ослабляет видимый свет. При постепенном уменьшении потенциала на катоде от $+2.7 \mathrm{~V}$ до нуля и затем до $-2.2 \mathrm{~V}$ электрохромное стекло последовательно проходит 4 состояния: темное теплое- светлое теплое-светлое холодноетемное холодное (рис. 16).

Четыре состояния - это весьма интересно, но не совсем понятно, когда нужно для оконного стекла состояние темное теплое, в котором окно не пропускает свет и пропускает БИК излучение - разве что в ясный солнечный холодный зимний день. Но зимой солнца и так не хватает, чтобы прятаться от его света.

Следует также отметить электрохромную двухкомпонентную гибридную систему, содержащую нанокристаллы ITO, диспергированные в полимерной матрице из политиофена [25]. Размер нанокристаллов $\sim 5 \mathrm{~nm}$. Толщина пленки $\sim 400 \mathrm{~nm}$. Нанокристаллы ІТО ослабляют БИК излучение с длиной волны более $1200 \mathrm{~nm}$ в результате плазмонного резонанса. При электрохимическом окислении под действием положительного напряжения пленка политиофена равномерно ослабляет видимый свет в результате поляронного эффекта.

Гибридная система при изменении напряжения имеет три характерных слабо выраженных состояния: светлое холодное-светлое теплое и темное холодное (рис. 8). Причем эти состояния при изменении потенциала располагаются в последовательности, отличной от аналогичных последовательностей в рассмотренных ранее электрохимических устройствах. Существенным недостатком гибридной системы является быстрая деградация ее свойств в электрохимической ячейке, а также быстрое разрушение полимерной матрицы под действием солнечного ультрафиолетового излучения [25]. Это отдаляет возможность использования такой системы в окнах до тех пор, пока эти недостатки не будут устранены.

\section{Свойства электрохромных ячеек-стекол. Изменение оптических свойств при изготовлении наноструктурного электрохромного электрода}

При изготовлении электрохромного электрода коллоидный раствор с нанокристаллами легированного диоксида титана $\mathrm{TiO}_{2}$ или с волокнистыми наночастицами восстановленного (легированного кислородными вакансиями) триоксида вольфрама $\mathrm{W}_{18} \mathrm{O}_{49}$ разбавляют органическим растворителем и наносят тонким слоем на стекло со слоем прозрачного электропроводящего материала (ITO или FTO). Затем пленку подвергают сушкеотжигу в потоке воздуха при температуре $400-430^{\circ} \mathrm{C}$, в результате чего формируется мезопористая структура. При этом оптические свойства пленки изменяются.

На рис. 19 приведены примеры изменения оптических характеристик пленок из волокнистых наночастиц $\mathrm{W}_{18} \mathrm{O}_{49}$ и из кристаллических наночастиц легированного ниобием диоксида титана $\mathrm{TiO}_{2}: \mathrm{Nb}$. Оптические свойства в процессе изготовления электрохромного электрода изменяются одинаково независимо от вида исходного материала. В исходном состоянии наночастицы обоих материалов содержат свободные электроны, и суспензия наночастиц в органическом растворителе ослабляет солнечное излучение в БИК диапазоне вследствие ЛПР.

При сушке пленки наночастиц $\mathrm{W}_{18} \mathrm{O}_{49}$ в потоке воздуха при комнатной температуре образуется регулярная матрица типа войлок с соприкасающимися волокнами. Плазмонное ослабление БИК излучения при этом снижается вследствие взаимодействия типа диполь-диполь между соседними наночастицами. При последующем спекании матрицы в потоке воздуха с температурой $400-430^{\circ} \mathrm{C}$ между соприкасающимися волокнами образуются плотные контакты и происходит окисление $\mathrm{W}_{18} \mathrm{O}_{49}\left(\mathrm{WO}_{2.72}\right)$ до состояния $\mathrm{WO}_{3-x}$, близкого к стехиометрическому $\mathrm{WO}_{3}$. В итоге сформированная наноструктурная пленка практически перестает поглощать БИК излучение вследствие устранения ЛПР. Высокая прозрачность электрохромного электрода в диапазонах 
видимого света и БИК излучения является необходимым свойством для применения в оконных стеклах. Таким свойством обладают мезопористые пленки как из легированного диоксида титана $\mathrm{TiO}_{2}$, так и триоксида вольфрама $\mathrm{WO}_{3-x}$ (рис. 19).

Восстановление способности плазмонного ослабления БИК излучения вследствие ЛПР достигается электрохимической инжекцией-экстракцией свободных электронов при подключении к источнику постоянного напряжения.

\section{Переходные процессы изменения оптических состояний при изменении напряжения на стекле.} При изменении напряжения на электрохромной ячейке происходит последовательный переход из светлого теплого в светлое холодное и далее в темное холодное состояния. На рис. $20, a-b$ показано циклическое изменение коэффициентов пропускания $\tau_{550}$ в диапазоне видимого света и $\tau_{1600}$ в диапазоне БИК излучения электрохромной ячейки с мезопористой пленкой из наночастиц $\mathrm{TiO}_{2}$ :Та, спектральные коэффициенты пропускания которой приведены на рис. 17. При циклическом изменении напряжения в диапазоне от 4 до $1.8 \mathrm{~V}$ происходит переход из светлого теплого в светлое холодное состояние и обратно. При циклическом изменении напряжения в диапазоне от 4 до $1.5 \mathrm{~V}$ происходит более глубокий переход из светлого теплого в темное холодное состояние.

При циклическом изменении напряжения в диапазоне $4-1.8 \mathrm{~V}$ изменение $\tau_{1600}$ происходит вследствие локализованного плазмонного резонанса при емкостном увеличении концентрации свободных электронов и образовании двойного электрического слоя на поверхности наночастиц. Этот процесс осуществляется очень быстро: двойной электрический слой формируется за $18.4 \mathrm{~s}$, а исчезает за $1.1 \mathrm{~s}$ (рис. 20, $b$ ).

При циклическом изменении напряжения в области 4-1.5 V изменение коэффициента пропускания $\tau_{550}$ в диапазоне видимого света происходит вследствие поляронного механизма ослабления излучения при внедрении ионов лития $\mathrm{Li}^{+}$внутрь кристаллической структуры наночастиц $\mathrm{TiO}_{2}$. Этот процесс протекает значительно медленнее, чем адсорбция $\mathrm{Li}^{+}$на поверхности наночастиц. Поэтому время затемнения $t_{c}=66.8 \mathrm{~s}$ более значительно по сравнению с $18.4 \mathrm{~s}$. Важно отметить, что затемнение электрохромной ячейки осуществляется за $66.8 \mathrm{~s}$, тогда как обратный процесс перехода ее в светлое состояние происходит почти в десять раз быстрее за $t_{b}=6.9 \mathrm{~s}$. Это свидетельствует о том, что внедрение ионов лития $\mathrm{Li}^{+}$внутрь кристаллической структуры наночастиц $\mathrm{TiO}_{2}$ происходит значительно медленнее, чем их экстракция.

Практически такие же результаты получены и для электрохромной ячейки, содержащей мезопористый электрод из наночастиц легированного ниобием диоксида титана $\mathrm{TiO}_{2}: \mathrm{Nb}$ (рис. 20,c). Здесь время перехода в диапазоне видимого света из светлого в затемненное состояние и обратно составляет $t_{c} / t_{b}=105 / 10 \mathrm{~s}$.

Размеры наночастиц в обеих ячейках практически одинаковы: размер наночастиц $\mathrm{TiO}_{2}: \mathrm{Ta}-11.6 \mathrm{~nm}$, наночастиц $\mathrm{TiO}_{2}: \mathrm{Nb} \sim 10 \mathrm{~nm}$.

В электрохромных ячейках с электродом из волокнистых наночастиц оксида вольфрама $\mathrm{WO}_{3-x}$ изменение оптических характеристик при циклическом изменении напряжения имеет несколько иной характер. На рис. 21, $a-c$ показаны такие результаты для электрохромной ячейки, спектральные коэффициенты пропускания которой приведены на рис. 15.

При циклическом изменении напряжения в диапазоне 4-2.8 V изменение коэффициента пропускания $\tau_{1200}$ БИК излучения и переход из светлого теплого в светлое холодное состояние происходит вследствие ЛПР при конденсаторном увеличении концентрации свободных электронов и образовании двойного электрического слоя на поверхности наночастиц. Этот процесс осуществляется очень быстро: двойной электрический слой формируется за $8 \mathrm{~s}$ и устраняется за $1.2 \mathrm{~s}$ (рис. 21, $a$ ). Эти данные аналогичны данным для ячейки с наночастицами $\mathrm{TiO}_{2}$ на рис. $20, b$.

При циклическом изменении напряжения в более значительном диапазоне 4-2.6 V происходит внедрениеэкстракция ионов лития $\mathrm{Li}^{+}$внутрь кристаллической структуры наночастиц $\mathrm{WO}_{3-x}$ и включается поляронный механизм ослабления БИК излучения. Поэтому изменение коэффициента пропускания $\tau_{1200}$ в диапазоне БИК излучения имеет более значительную величину и происходит значительно медленнее (рис. 21, b).

При циклическом изменении напряжения в диапазонах 4-2 V осуществляется обратимый переход из светлого в темное состояние (рис. $21, c$ ). Причем переход из темного в светлое состояние может быть разделен на два этапа. После включения напряжения $4 \mathrm{~V}$ коэффициент светопропускания $\tau_{633}$ увеличивается резко вначале и затем более медленно. Это соответствует быстрому процессу десорбции ионов $\mathrm{Li}^{+}$с поверхности наночастиц вначале, с последующим более медленным процессом их экстракции из кристаллической структуры. При этом переход из светлого в темное состояние осуществляется за $21 \mathrm{~s}$, а обратный переход значительно длительнее за $85 \mathrm{~s}-t_{c} / t_{b}=21 / 85 \mathrm{~s}$. Это свидетельствует о том, что для волокнистых нанокристаллов из $\mathrm{WO}_{3-x}$ внедрение ионов лития $\mathrm{Li}^{+}$внутрь кристаллической структуры наночастиц $\mathrm{WO}_{3-x}$ происходит значительно быстрее, чем их экстракция $-t_{c} / t_{b}<1$.

В этом и заключается различие между нанокристаллами из легированного диоксида $\mathrm{TiO}_{2}$ и волокнистыми наночастицами из $\mathrm{WO}_{3-x}$. Для нанокристаллов из легированного диоксида $\mathrm{TiO}_{2}$ внедрение ионов $\mathrm{Li}^{+}$в кристаллическую решетку происходит медленнее, чем их экстракция $t_{c} / t_{b}>1$, для волокнистых наночастиц $\mathrm{WO}_{3-x}$ наоборот, внедрение ионов $\mathrm{Li}^{+}$в кристаллическую решетку происходит быстрее, чем их экстракция $t_{c} / t_{b}<1$. 

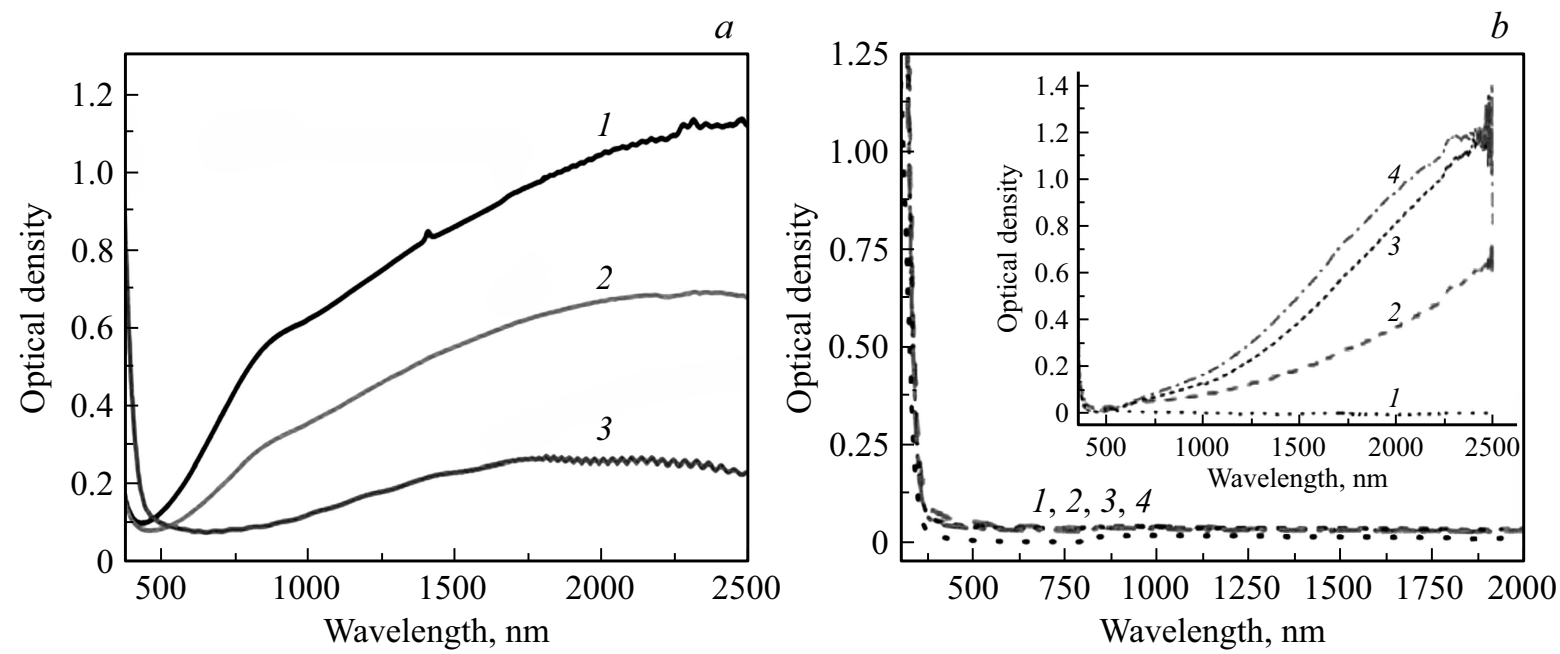

Рис. 19. Спектры ослабления излучения слоем наночастиц на различных этапах изготовления наноструктурного электрода: (a) волокнистые наночастицы $\mathrm{W}_{18} \mathrm{O}_{49}$ [4]. 1 - дисперсия наночастиц в растворителе; 2 - после сушки эмульсии наночастиц на стекле с ITO покрытием в потоке воздуха с температурой $20^{\circ} \mathrm{C} ; 3$ - после сушки-отжига в потоке нагретого до $400-430^{\circ} \mathrm{C}$ воздуха. $(b)$ нанокристаллы легированной двуокиси титана $\mathrm{TiO}_{2}: \mathrm{Nb}$ в растворителе (на вставке) и после сушки-отжига в потоке нагретого до $430^{\circ} \mathrm{C}$ воздуха [17]. Содержание легирующей добавки $\mathrm{Nb}: 0 \%$ (1), 5 (2), 10 (3), 15\% (4).
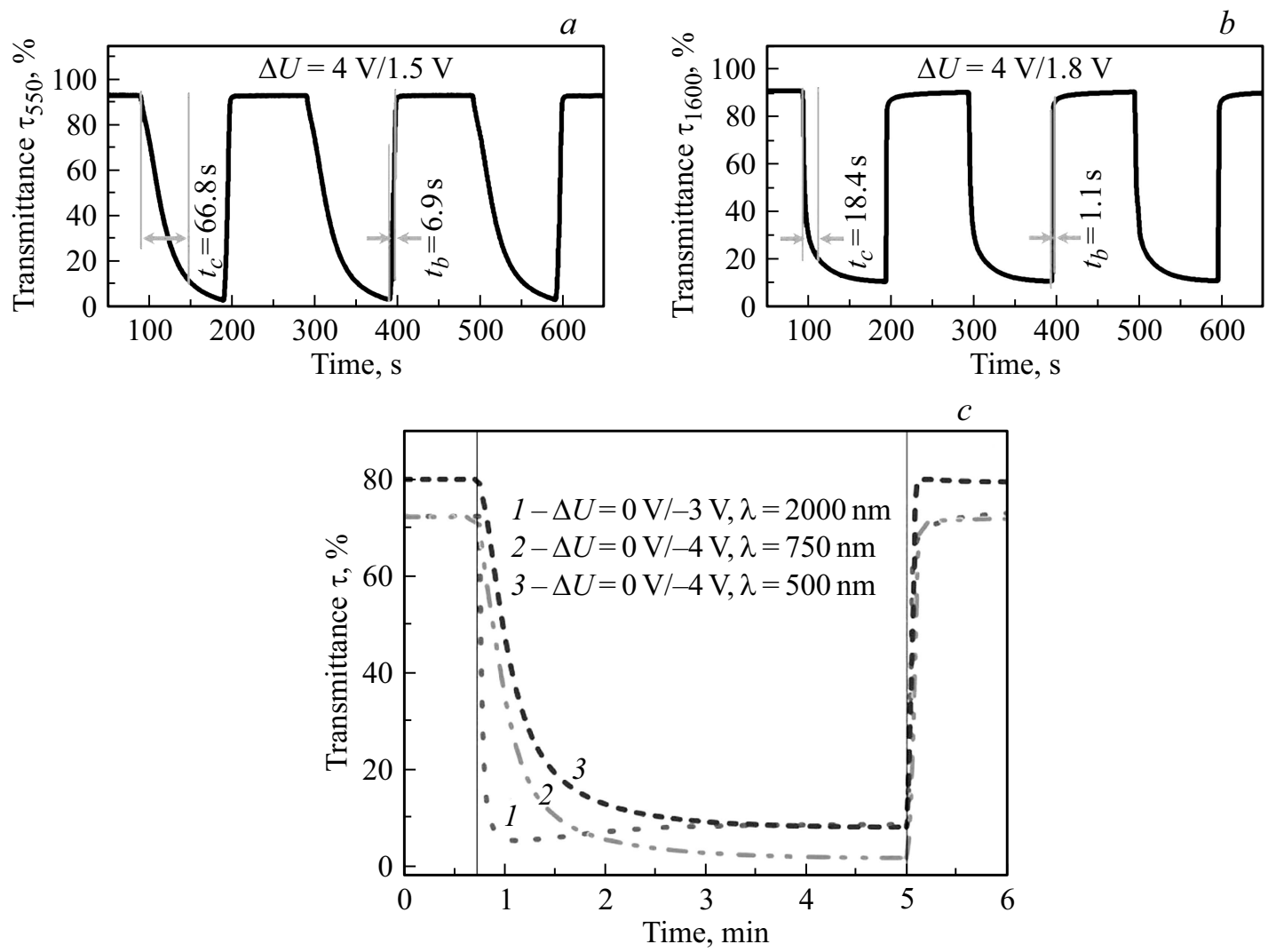

Рис. 20. Изменение локальных коэффициентов пропускания наноструктурных электрохромных электродов из легированного диоксида титана $\mathrm{TiO}_{2}$ в ходе циклических переключений под действием прямоугольной волны изменения напряжения $\Delta U$. $(a, b)-$ $\mathrm{TiO}_{2}: \mathrm{Ta}-13 \%$ [22], $(c)-\mathrm{TiO}_{2}: \mathrm{Nb}-10 \%$ [17]. $\Delta U=4 \mathrm{~V} / 1.5 \mathrm{~V}(a), 4 \mathrm{~V} / 1.8 \mathrm{~V}(b)$.

Продолжительность циклических переходов из светлого в темное состояние и обратно $t_{c} / t_{b}$ определяется скоростью внедрения-экстракции ионов $\mathrm{Li}^{+}$в кристал- лические решетки наночастиц. Эта скорость для наночастиц одинаковой кристаллической структуры зависит от формы и размера частиц. Чем меньше размер наноча- 

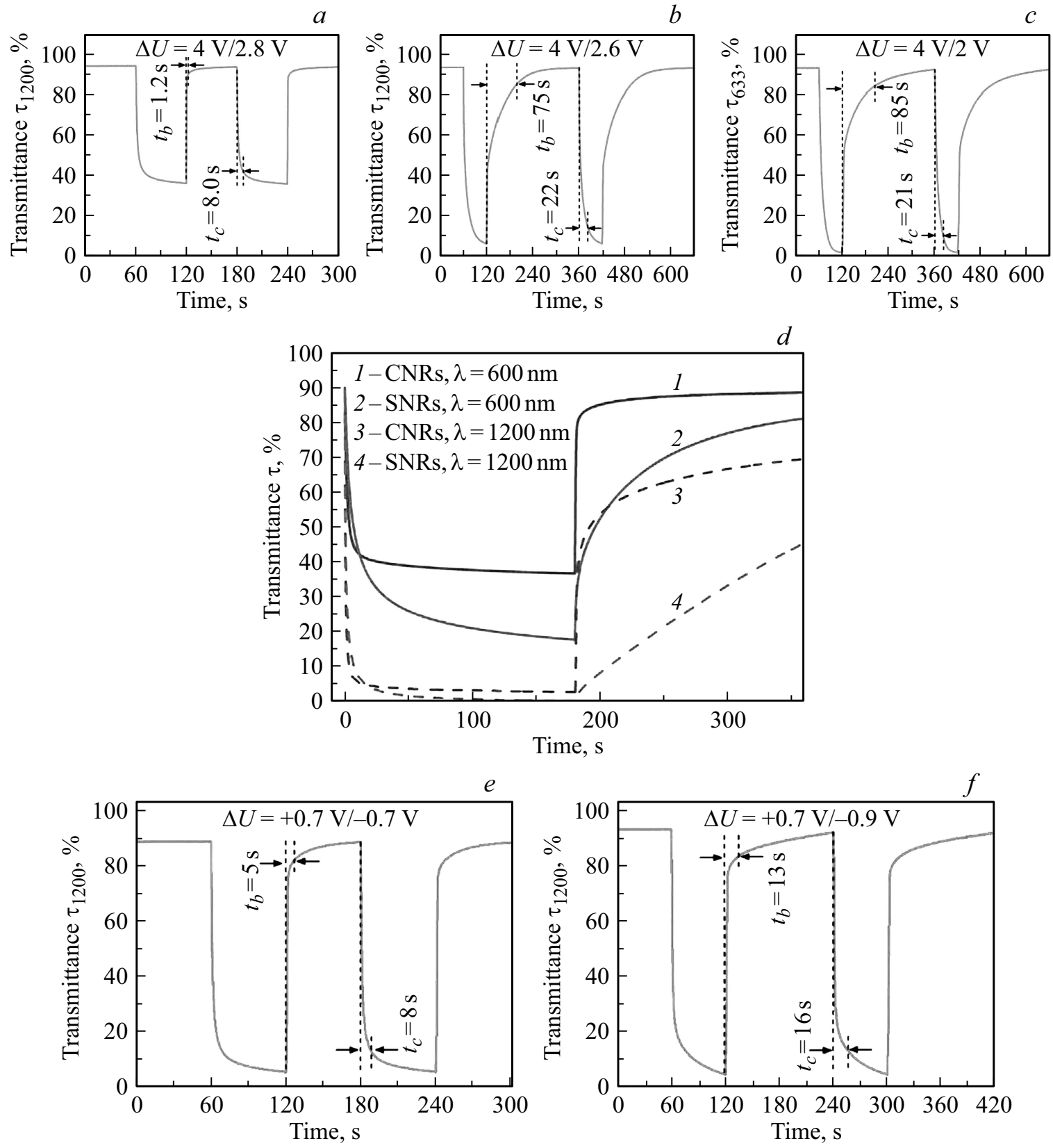

Рис. 21. Изменение локальных коэффициентов пропускания электрохромных электродов из волокнистых нанокристаллов восстановленного триоксида вольфрама $\mathrm{WO}_{3-x}$ в ходе циклических переключений под действием прямоугольной волны изменения напряжения $\Delta U .(a-c)$ Электролит с ионами $\mathrm{Li}^{+} . \Delta U=4 \mathrm{~V} / 2.8 \mathrm{~V}(a) ; \Delta U=4 \mathrm{~V} / 2.6 \mathrm{~V}(b) ; \Delta U=4 \mathrm{~V} / 2 \mathrm{~V}(c)$ [4]. (d) Электролит с ионами $\mathrm{Li}^{+} . \Delta U=+1 \mathrm{~V} /-0.5 \mathrm{~V} .1,3$ - трубчатые вырезанные наностержни; 2, 4 - сплошные наностержни [18]. (e-f) Электролит с ионами $\mathrm{Al}^{3+} . \Delta U=+0.7 \mathrm{~V} /-0.7 \mathrm{~V}(e) ; \Delta U=+0.7 \mathrm{~V} /-0.9 \mathrm{~V}(f)[23]$.

стиц и чем больше их поверхность, чем больше отношение поверхности к их объему, тем быстрее происходят процессы внедрения-экстракции ионов $\mathrm{Li}^{+}$в них.

Указанный эффект отчетливо проявляется на рис. $21, d$. Здесь приведены результаты по циклическому изменению оптических характеристик двух электрохромных ячеек с электродом из волокнистых наночастиц из $\mathrm{WO}_{3-x}$. Наночастицы имеют одинаковую длину около $80 \mathrm{~nm}$, но различную форму. Частицы SNRs сплошные диаметром $3 \mathrm{~nm}$, а частицы CNRs имеют форму половинок трубок диаметром $8.5 \mathrm{~nm}$ с толщиной стенки $3 \mathrm{~nm}$. Удельная поверхность электродов из CNRs частиц значительно превышает аналогичную характеристику для электродов из SNRs частиц - 48 против $27 \mathrm{~m}^{2} / \mathrm{g}$. Спектральные коэффициенты пропускания этих двух электрохромных ячеек приведены на рис. 13.

Приведенные на рис. 21, $d$ данные свидетельствуют о значительном влиянии формы наночастиц на характер изменения оптических характеристик при циклическом изменении напряжения. При одинаковых прочих 
условиях переход из светлого в темное состояние и обратно осуществляется быстрее для частиц CNRs c развитой поверхностью: время перехода из светлого в темное состояние и обратно в диапазоне видимого света при $\lambda=600 \mathrm{~nm}$ для электрохромного электрода из частиц CNRs составляет $t_{c} / t_{b}=12 / 12 \mathrm{~s}$ против $t_{c} / t_{b}=98 />1200 \mathrm{~s}$ для электрода из частиц SNRs.

Необходимо заметить также, что данные на рис. $21, d$ по времени перехода $t_{b}$ из темного в светлое состояние при $\lambda=1200 \mathrm{~nm}$ выпадают из общей закономерности - для обоих видов электродов переход из темного в светлое состояние в области БИК излучения при $\lambda=1200 \mathrm{~nm}$ значительно медленнее, чем в диапазоне видимого света при $\lambda=600 \mathrm{~nm}$.

В заключение следует отметить, что для окон не требуется малая продолжительность (менее $\sim 30 \mathrm{~s}$ ) переходных процессов при изменении оптических состояний вследствие медленной адаптации глаз человека при изменении освещенности.

\section{Циклическая стабильность}

Неизменность оптических свойств при повторяющихся циклических переключениях (циклическая стабильность) является важным требованием для электрохромного стекла, так как определяет его максимальный срок службы. Из расчета одно переключение в сутки при тридцатилетнем сроке эксплуатации оптические свойства не должны снижаться более чем на 10\% после 11000 переключений.

Приведенные в табл. 1 данные свидетельствуют о достаточно хорошей циклической стабильности исследованных электрохромных устройств с однокомпонентными электродами.

Изменение (модуляция) коэффициента пропускания видимого света электрохромного устройства с мезопористым электродом из волокнистых наночастиц $\mathrm{WO}_{3-x}$ после 1000 циклических переключений снизилось на 8.3\% [4]. На рис. 22 показано изменение спектральных коэффициентов пропускания после 1000 циклических переключений. Модуляция коэффициента пропускания во всем спектре солнечного излучения снижается. При этом спектральный коэффициент пропускания в светлом теплом состоянии снижается после 1000 переключений, а коэффициенты пропускания в светлом холодном и темном холодном состояниях возрастают.

Модуляция светопропускания устройства с мезопористым электродом из наноночастиц $\mathrm{TiO}_{2}$ : Та уменьшилась после 2000 переключений всего лишь на 1.3\% [22].

\section{Влияние электролита}

Электрохромные стекла оконного размера можно изготовить только при использовании твердого или пластифицированного электролита. Существенное достоинство мезопористой структуры электрохромного

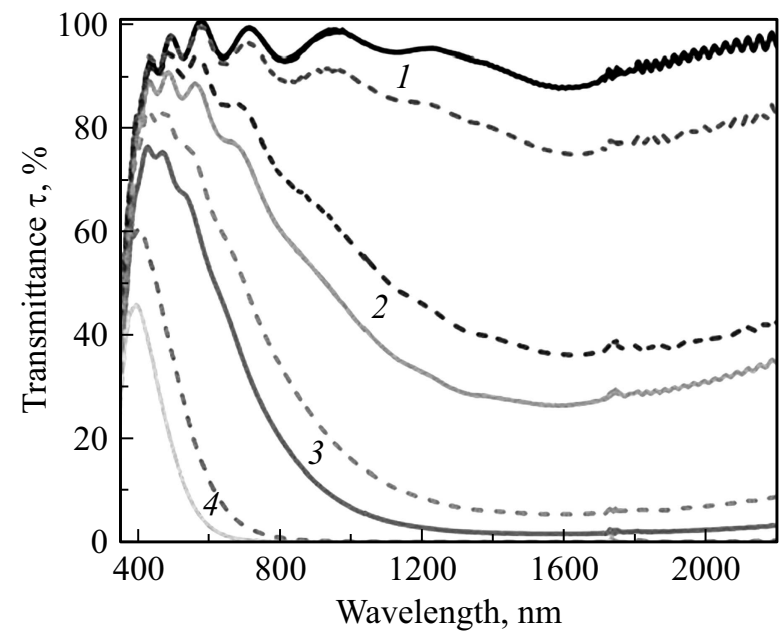

Рис. 22. Спектры пропускания электрохромного устройства с наноструктурным $\mathrm{WO}_{3-x}$ электродом в результате многократных циклических переключений в фиксированных оптических состояних при значениях потенциала электрода [4]: 4.0 (1), 2.8 (2), 2.6 (3), $2 \mathrm{~V}(4)$. Сплошные линии — начальное состояние, штриховые - после 1000 циклических переключений.

электрода состоит в том, что она может быть заполнена пластифицированным полимерным электролитом. Это выполнили авторы работы [15]. В итоге получено электрохромное стекло с полимерным гельэлектролитом, что создает реальные предпосылки для коммерческой реализации таких устройств оконного размера.

Значительное влияние на характер электрохромного процесса оказывает состав электролита. Так, в электрохромном стекле с электродом из $\mathrm{WO}_{3-x}$ эффект раздельного модулирования БИК излучения и видимого света удалось полностью реализовать только при добавлении в электролит $\mathrm{LiClO}_{4}$ значительной доли йодистого лития LiI [16]. Была использована смесь $0.7 \mathrm{M}$ $\mathrm{LiClO}_{4}+0.3 \mathrm{M} \mathrm{LiI,} \mathrm{растворенная} \mathrm{в} \mathrm{смеси} \mathrm{пропилен-}$ карбоната и ацетонитрила $(70: 30)$. При отсутствии в смеси соли LiI или низком ее содержании (например, 0.005 M LiI) ослабление видимого света не отмечено.

Во всех первых 14 исследованиях использовались электролиты с одновалентными ионами лития $\mathrm{Li}^{+}$. При этом отмечены чрезмерная длительность переходных процессов при переключении оптических состояний и недостаточная циклическая стабильность.

Предполагается, что основная причина недостаточной циклической стабильности кроется в постепенном разрушении кристаллической структуры наночастиц вследствие ее перестройки при многократных фазовых превращениях в ходе циклических переключений. Причина длительности переходных режимов при циклических переключениях заключается в низкой скорости диффузии многочисленных ионов при их внедрении-экстрации в кристаллическую структуру. 
Оба указанных недостатка можно исправить, если число ионов удастся существенно снизить за счет использования многовалентных ионов малого размера. Например, для нейтрализации отрицательного заряда наночастицы трехвалентных ионов требуется в три раза меныше, чем одновалентных. Соответственно снижается перестройка кристаллической структуры при внедренииэкстракции меньшего количества ионов и уменьшается продолжительность этих процессов.

Среди многовалентных ионов наиболее подходящими являются трехвалентные ионы алюминия $\mathrm{Al}^{3+}$. Этот металл имеет низкую стоимость, а его ионный радиус $0.53 \AA$ меньше ионного радиуса лития, равного $0.76 \AA$. В настоящее время известен только один наноструктурный электрохромный материал, моноклинный волокнистый $\mathrm{WO}_{3-x}$, который активируется ионами обоих типов $\mathrm{Al}^{3+}$ и $\mathrm{Li}^{+}$.

Исследования электрохромных ячеек с одинаковыми наноструктурными электродами их волокнистого $\mathrm{WO}_{3-x}$ и различными электролитами, содержащими ионы $\mathrm{Li}^{+}$ и $\mathrm{Al}^{3+}$, выполнены авторами работ [4,23] соответственно. Результаты приведены в табл. 1,2, спектры на рис. 15 и рис. 18, изменение локальных коэффициентов пропускания в ходе циклических переключений - на рис. $21, a-c$ и $21, e-f$. Оптические характеристики обоих устройств практически не отличаются. Но при использовании электролита с трехвалентными ионами $\mathrm{Al}^{3+}$ существенно улучшается циклическая стабильность и сокращается продолжительность переходных процессов. Так, при использовании электролита с ионами лития $\mathrm{Li}^{+}$время перехода из светлого в темное состояние и обратно равно $t_{c} / t_{b}\left(\mathrm{Li}^{+}\right)=21 / 85 \mathrm{~s}$ (рис. $21, c$ ), тогда как при использовании электролита с трехвалентными ионами $\mathrm{Al}^{3+}$ обе эти величины значительно меньше $t_{c} / t_{b}$ $\left(\mathrm{Al}^{3+}\right)=16 / 13 \mathrm{~s}$ (рис. $\left.21, f\right)$. При этом изменилось соотношение между этими временами: $t_{c} / t_{b}\left(\mathrm{Li}^{+}\right)=21 / 85<1$, тогда как $t_{c} / t_{b}\left(\mathrm{Al}^{3+}\right)=16 / 13>1$. Отмечено также и значительное улучшение циклической стабильности. При использовании $\mathrm{Li}^{+}$модуляция светопропускания снизилась на 8.3\% после 1000 циклических переключений, тогда как при использовании $\mathrm{Al}^{3+}$ модуляция светопропускания уменьшилась на 7.6\% после вдвое большего числа 2000 переключений.

В заключение следует отметить, что в поисковых исследованиях был испытан образец твердотельного электрохромного стекла с полимерным гель-электролитом. В сочетании с однокомпонентными наноструктурными электродами из восстановленного триоксида вольфрама или легированного диоксида титана это создает реальные предпосылки для изготовления опытных образцов и последующей коммерческой реализации электрохромных стекол оконного размера. Основное препятствие значительная сложность изготовления электрохромного стекла с наноструктурным мезопористым электродом.

\section{Список литературы}

[1] Майоров В.А. // Опт. и спектр. 2018. Т. 124. № 4. С. 559. doi 10.21883/OS.2018.04.45759.240-17

[2] Granqvist C.G. // Thin Solid Films. 2014. V. 564. N 1. P. 1. doi 10.1016/j.tsf.2014.02.002

[3] Granqvist C.G., Arvizu M.A., Pehlivan I.B., Qu H.-Y., Wen R.T., Niklasson G.A. // Electrochimica Acta. 2018. V. 259. P. 1170. doi 10.1016/j.electacta.2017.11.169

[4] Zhang S., Cao S., Zhang T., Yao Q., Fisher A., Lee J.Y. // Materials Horizons. 2018. V. 5. N 2. P. 291. doi 10.1039/C7MH01128H

[5] Giannuzzi R., Da Silva R., Barawi M., De Trizio L., Veramonti G., Qualtieri A., Manna L., Manca M. // ECS Transactions. 2017. V. 77. N 11. P. 1671. doi 10.1149/07711.1671ecst

[6] Майоров B.A. // Светопрозрачные конструкции. 2016. № 1. C. 21.

[7] Майоров B.A. // Светопрозрачные конструкции. 2016. № 2. C. 8.

[8] Pattathil P., Giannuzzi R., Manca M. // Nano Energy. 2016. V. 30. P. 242. doi 10.1016/j.nanoen.2016.10.013

[9] Kriegel I., Scotognella F., Manna L. // Phys. Rep. 2017. V. 674. N 1. P. 1. doi 10.1016/j.physrep.2017.01.003

[10] Agrawal A., Cho S.H., Zandi O., Ghosh S., Johns R.W., Milliron D.J. // Chem. Rev. 2018. V. 118. N 6. P. 3121. doi 10.1021/acs.chemrev.7b00613

[11] Adachi K., Asahi T. // J. Mater.Research. 2012. V. 27. N 6. P. 965. doi 10.1557/jmr.2012.25

[12] Cao S., Zhang S., Zhang T., Fishe A., Lee J.Y. // J. Materials Chemistry C. 2018. V. 6. N 15. P. 4007. doi 10.1039/C8TC00185E

[13] Llordés A., Garcia G., Gazquez J., Milliron D.J. // Nature. 2013. V. 500. P. 323. doi 10.1038/nature 12398

[14] Kim J., Ong G.K., Wang Y., LeBlanc G., Williams T.E., Mattox T.M., Helms B.A., Milliron D.J. // Nano Letters. 2015. V. 15. N 8. P. 5574. doi 10.1021/acs.nanolett.5b02197

[15] Llordés A., Wang Y., Fernandez-Martinez A., Xiao P., Lee T., Poulain A., Zandi O., Saez Cabezas C.A., Henkelman G., Milliron D.J. // Nature Materials. 2016. V. 15. P. 1267. doi 10.1038/nmat4734

[16] Pattathil P., Scarfiello R., Giannuzzi R., Veramonti G., Sibillano T., Qualtieri A., Giannini C., Cozzoli P.D., Manca M. // Nanoscale. 2016. V. 8. P. 20056. doi 10.1039/C6NR07221F

[17] Barawi M., De Trizio L., Giannuzzi R., Veramonti G., Manna L., Manca M. // ACS Nano. 2017. V. 11. N 4. P. 3576. doi 10.1021/acsnano.6b06664

[18] Giannuzzi R., Scarfiello R., Sibillano T., Grillo V., Giannini C., Cozzoli P.D., Manca M. // Nano Energy. 2017. V. 41. N 3. P. 634. doi 10.1016/j.nanoen.2017.09.058

[19] Barawi M., Veramonti G., Epifani M., Giannuzzi R., Sibillano T., Giannini C., Rougier A., Manca M. // J. Materials Chemistry A. 2018. V. 6. N 22. P. 10201. doi 10.1039/C8TA02636J

[20] Wang Z., Zhang Q., Cong S., Chen Z., Zhao J., Yang M., Zheng Z., Zeng S., Yang X., Geng F., Zhao Z. // Advanced Optical Materials. 2017. V. 5. N 11. P. 1700194. doi 10.1002/adom.201700194

[21] Gu H., Guo C., Zhang S., Bi L., Li T., Sun T., Liu S. // ACS Nano. 2018. V. 12. N 1. P. 559. doi 10.1021/acsnano.7b07360 
[22] Cao S., Zhang S., Zhang T., Lee J.Y. // Chemistry Materials. 2018. V. 30. N 14. P. 4838.

doi 10.1021/acs.chemmater.8b02196

[23] Zhang S., Cao S., Zhang T., Fisher A., Lee J.Y. // Energy Environmental Science. 2018. V. 11. N 10. P. 2884. doi 10.1039/C8EE01718B

[24] Dahlman C.J., Tan Y., Marcus M.A., Milliron D.J. // J. American Chemical Society. 2015. V. 137. N 28. P. 9160. doi 10.1021/jacs.5b04933

[25] Barile C.J., Slotcavage D.J., McGehee M.D. // Chemistry Materials. 2016. V. 28. N 5. P. 1439. doi 10.1021/acs.chemmater

[26] Heo S., Kim J., Ong G.K., Milliron D.J. // Nano Letter. 2017. V. 17. N 9. P. 5756. doi 10.1021/acs.nanolett.7b02730 